\title{
Mechanism of Rectification in Tunneling Junctions Based on Molecules with Asymmetric Potential Drops
}

\section{Citation}

Nijhuis, Christian A., William F. Reus and George M. Whitesides. Mechanism of rectification in tunneling junctions based on molecules with asymmetric potential drops. Journal of the American Chemical Society 132(51): 18386-18401.

\section{Published Version}

doi:10.1021/ja108311j

\section{Permanent link}

http://nrs.harvard.edu/urn-3:HUL.InstRepos:9821907

\section{Terms of Use}

This article was downloaded from Harvard University's DASH repository, and is made available under the terms and conditions applicable to Open Access Policy Articles, as set forth at http:// nrs.harvard.edu/urn-3:HUL.InstRepos:dash.current.terms-of-use\#OAP

\section{Share Your Story}

The Harvard community has made this article openly available.

Please share how this access benefits you. Submit a story.

\section{Accessibility}




\title{
The Mechanism of Rectification in Tunneling Junctions Based on Molecules with Asymmetric Potential Drops
}

Christian A. Nijhuis, William F. Reus, and George M. Whitesides*

Department of Chemistry and Chemical Biology, Harvard University, 12 Oxford St, Cambridge, MA 02138, USA

corresponding author:

Tel.: 6174589430

Fax.: 6174589857

e-mail: gwhitesides@gmwgroup.harvard.edu

\begin{abstract}
This paper proposes mechanism for the rectification of current by selfassembled monolayers (SAMs) of alkanethiolates with $\mathrm{Fc}$ head groups $\left(\mathrm{SC}_{11} \mathrm{Fc}\right)$ in SAMbased tunneling junctions with ultra-flat Ag bottom-electrodes and liquid metal $\left(\mathrm{Ga}_{2} \mathrm{O}_{3} / \mathrm{EGaIn}\right)$ top-electrodes. A systematic physical-organic study, based on statistically large numbers of data $(\mathrm{N}=300-1000)$ reached the conclusion that only one energetically accessible molecular orbital (the $\mathrm{HOMO}$ of the $\mathrm{Fc}$ ) is necessary to obtain large rectification ratios $R \approx 1.0 \times 10^{2}(R=|J(-\mathrm{V})| / J(\mathrm{~V}) \mid$ at $\pm 1 \mathrm{~V})$. Values of $R$ are lognormally distributed, with a log-standard deviation of 3.0. The HOMO level has to be positioned spatially asymmetrically inside the junctions (in these experiments, in contact with the $\mathrm{Ga}_{2} \mathrm{O}_{3} / \mathrm{EGaIn}$ top-electrode, and separated from the $\mathrm{Ag}$ electrode by the $\mathrm{SC}_{11}$
\end{abstract}


moiety), and energetically below the Fermi levels of both electrodes, to achieve rectification. The HOMO follows the potential of the Fermi level of the $\mathrm{Ga}_{2} \mathrm{O}_{3} / \mathrm{EGaIn}$ electrode; it overlaps energetically with both Fermi levels of the electrodes only in one direction of bias.

\section{Introduction}

This paper proposes a mechanism for the large rectification of currents observed in tunneling junctions based on self-assembled monolayers (SAMs) of 11-(ferrocenyl)-1undecanethiol $\left(\mathrm{SC}_{11} \mathrm{Fc}\right)$ on template-stripped silver $\left(\mathrm{Ag}^{\mathrm{TS}}\right)$ using eutectic indium-gallium (EGaIn) alloy with a surface layer of $\mathrm{Ga}_{2} \mathrm{O}_{3}$ as a top-contact. We call these junctions " $\mathrm{Ag}^{\mathrm{TS}}-\mathrm{SC}_{11} \mathrm{Fc} / / \mathrm{Ga}_{2} \mathrm{O}_{3} / \mathrm{EGaIn}$ " and consider the molecules in the junction to comprise two sections: an "insulating" section - an alkyl chain - and a "conductive" section - a ferrocene $(\mathrm{Fc})$ head group. Using this system as a platform for physical-organic studies of charge transport across SAMs, we have tested the mechanism of rectification through controlled variation of the structure of the SAM. Specifically, we have independently varied the lengths of the conducting and insulating sections of the SAMs, changed the position of the conductive section within the SAM, and left out the conductive section entirely (Fig. 1).

The principal metric used in these studies was the rectification ratio, $R$ (eq. 1), evaluated at $\pm 1 \mathrm{~V}$ (where $|J(\mathrm{~V})|$ is the absolute value of current density $\left(\mathrm{A} / \mathrm{cm}^{2}\right)$ as a function of voltage, $\mathrm{V})$. Tunneling junctions incorporating $\mathrm{SAMs}$ of $\mathrm{SC}_{11} \mathrm{Fc}$, or $\mathrm{SAMs}$ with two directly coupled $\mathrm{Fc}$ moieties (biferrocene $\equiv \mathrm{Fc}_{2}$, Fig. 1), rectified currents with rectification ratios $R>10^{2}$. Junctions incorporating SAMs of n-undecanethiolate 
$\left(\mathrm{SC}_{10} \mathrm{CH}_{3}\right)$ and n-pentadecanethiolate $\left(\mathrm{SC}_{14} \mathrm{CH}_{3}\right.$, a saturated molecule comparable in length to $\mathrm{SC}_{11} \mathrm{Fc}$ ) - written as $\mathrm{Ag}^{\mathrm{TS}}-\mathrm{SC}_{10} \mathrm{CH}_{3} / / \mathrm{Ga}_{2} \mathrm{O}_{3} / \mathrm{EGaIn}$ and $\mathrm{Ag}^{\mathrm{TS}}$ $\mathrm{SC}_{14} \mathrm{CH}_{3} / / \mathrm{Ga}_{2} \mathrm{O}_{3} / \mathrm{EGaIn}$, respectively - did not rectify; thus, a Fc group is required for rectification in these experiments. Junctions incorporating SAMs with the Fc moiety placed in the middle of the SAM (Fig. 1) did not rectify; thus, asymmetric placement of the $\mathrm{Fc}$ group in the junction also seems to be required.

$$
R=|J(-\mathrm{V})| /|J(\mathrm{~V})|
$$

Our experiments were based in the idea that changing the lengths of the insulating and conductive portions of the molecular components of the SAMs, and varying the proximity of the conductive portion to each electrode, would change i) the width and shape of the tunneling barrier presented by these SAMs, and ii) the relative electronic coupling to each electrode of the highest occupied molecular orbital (HOMO) of the Fc or $\mathrm{Fc}_{2}$ moiety. ${ }^{1,2}$

The results suggest a mechanism for rectification that is similar to that proposed by the groups of Williams et al. ${ }^{1}$ and Baranger et al. ${ }^{2}$ (see below). This mechanism is based on a HOMO that is more strongly coupled to one electrode than to the other; it becomes energetically accessible more easily at forward bias $\left(V_{\mathrm{f}}, \mathrm{Ga}_{2} \mathrm{O}_{3} / \mathrm{EGaIn}\right.$ is negatively biased) than at reverse bias $\left(V_{\mathrm{r}}, \mathrm{Ga}_{2} \mathrm{O}_{3} / \mathrm{EGaIn}\right.$ is positively biased). At sufficient forward bias - that is, when this Fc HOMO is energetically accessible - the conductive portion of the SAM does not significantly hinder charge-transport, and the insulating $\left(\mathrm{CH}_{2}\right)_{\mathrm{n}}$ portion of the SAM constitutes the sole tunneling barrier presented by the SAM. At reverse bias, the HOMO is inaccessible and both the conductive and insulating portions of the SAM together (the entire $\mathrm{C}_{11} \mathrm{Fc}$ group) form the barrier to 
Figure 1: Idealized schematic representations of the tunneling junctions consisting of $\mathrm{Ag}^{\mathrm{TS}}$ bottom-electrodes, $\mathrm{SAMs}$ of $\mathrm{SC}_{11} \mathrm{Fc}(\mathrm{A}), \mathrm{SC}_{14} \mathrm{CH}_{3}(\mathrm{~B}), \mathrm{SC}_{10} \mathrm{CH}_{3}(\mathrm{C}), \mathrm{SC}_{6} \mathrm{FcC}_{5} \mathrm{CH}_{3}$ (D), $\mathrm{SC}_{11} \mathrm{Fc}_{2}(\mathrm{E})$, or $\mathrm{SC}_{9} \mathrm{Fc}(\mathrm{F})$, and $\mathrm{Ga}_{2} \mathrm{O}_{3} / \mathrm{EGaIn}$ top-electrodes (Figure 2 shows more realistic schematic representations of the junctions). The outer layer of $\mathrm{Ga}_{2} \mathrm{O}_{3} / \mathrm{EGaIn}$ is a layer of $\mathrm{Ga}_{2} \mathrm{O}_{3}$ of roughly 1- $2 \mathrm{~nm}$ thick (see below). 

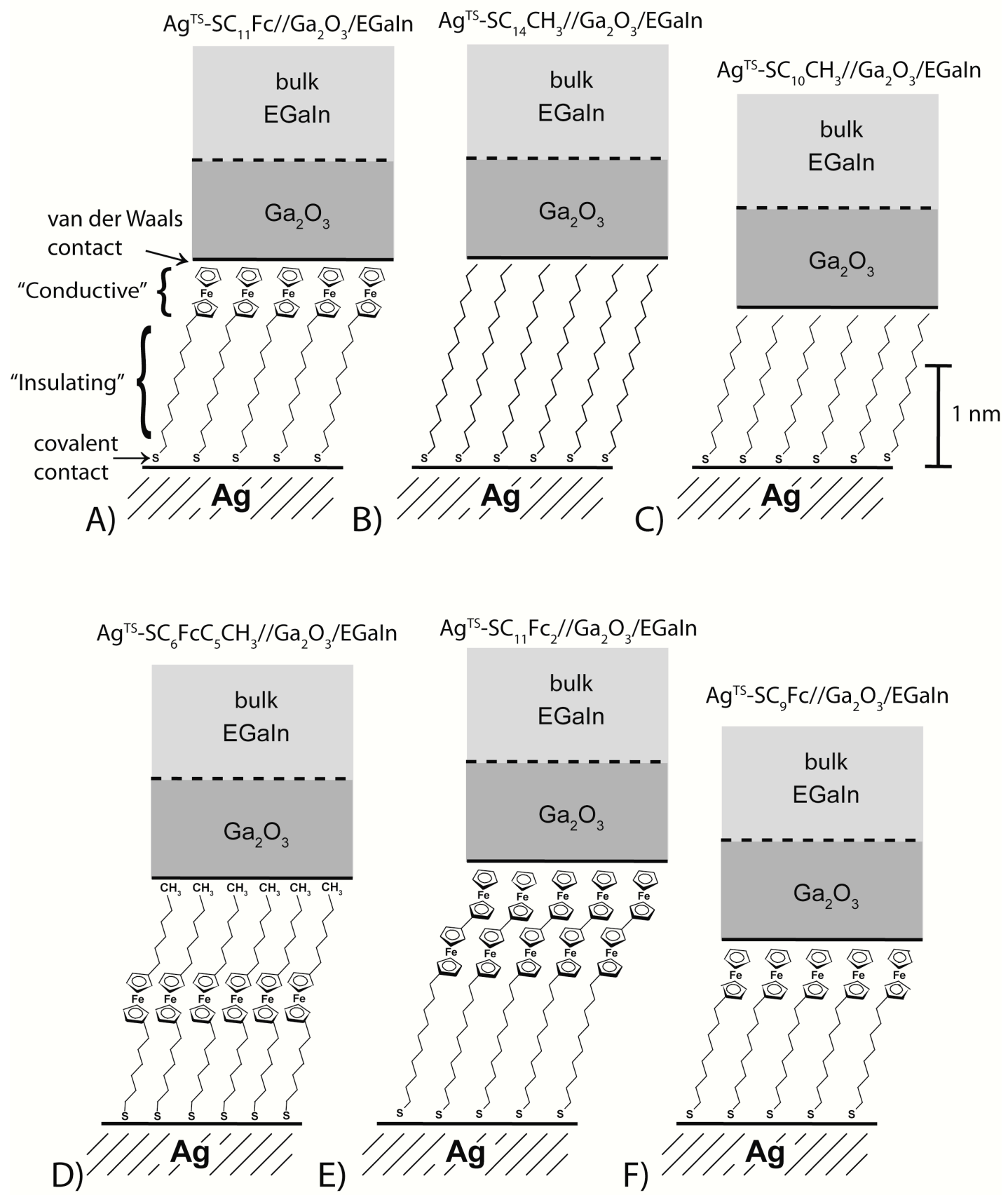
tunneling. Thus, charges encounter a wider tunneling barrier at reverse bias than at forward bias. Since tunneling current decreases exponentially with increasing width of the barrier, a higher current flows at forward bias than at reverse bias, and the junction rectifies.

The yield of working junctions in these systems was high $(70-90 \%$ of all junctions did not short-circuit, and were stable for at least $21 J(V)$ traces; the remaining $10-30 \%$ shorted or were unstable). We, thus, were able to generate and analyze hundreds of data $(\mathrm{N}=300-1000)$ for each SAM. The current densities and the values of $R$ both followed a log-normal distribution.

By demonstrating rectification in a system with a single accessible molecular orbital, and by elucidating the mechanism of rectification in this system, we are able to resolve a long-standing dispute within the molecular electronics community: ${ }^{3,4}$ namely, whether molecular rectification requires both a donor and an acceptor moiety (see below), or whether it can occur with a single, asymmetrically-placed, accessible molecular orbital. We conclude the latter: the simultaneous presence of a donor and an acceptor (that is, an embedded dipole) is not required (although it may also result in rectification).

Measurements of charge transport through large-area junctions have been notoriously irreproducible, due (plausibly) to variations in the substrate, the SAM, and the top contact. Measurements of $R$ circumvent many of the artifacts encountered in measurements of $J$. Because the substrate, SAM, and top contact remain the same (and incorporate the same defects) across the range of biases applied, the current at positive bias serves as an internal standard against which to examine the current at negative bias (or vice versa). 
A fundamental understanding of the mechanism of rectification in these junctions is important in molecular electronics, and more broadly, in understanding charge transport through organic matter (e.g., in biochemistry, ${ }^{5}$ energy harvesting, ${ }^{6}$ information storage, ${ }^{7,8}$ sensing ${ }^{9}$ etc.). Charge transport through SAMs of structurally complex molecules catenanes, ${ }^{10,11}$ rotaxanes, ${ }^{12}$ and molecules containing electron donors and acceptors ${ }^{4,13}$ has been studied extensively. The complexity of these molecules, and the nearly complete lack of structural information concerning SAMs that incorporate them, makes interpretation of data difficult, and identification of the correct mechanism for charge transport across them ambiguous. Lee et al. ${ }^{14}$ have recognized that most of these systems involved junctions that are prepared by processes that, as we now know (but did not know at the time of the experiments), give very low yields (often $<1-5 \%$ ) of "working junctions" (usually, "working junction" is, itself, an undefined phrase). ${ }^{15}$ As a result, distinguishing interesting phenomena - such as rectification or switching - from behaviors that are artifactual - such as reaction of metal with the organic molecules of the $\mathrm{SAM}^{16,17}$ and the formation and dissolution of metal filaments ${ }^{18,19}$ - has been very difficult. Many papers either do not report meaningful statistics, or fail, in the first place, to collect sufficient numbers of data to support a statistical analysis of error and uncertainty. ${ }^{14}$ To obtain convincing data in what is admittedly still an experimentally difficult area, to compensate for defects and anomalies in the junctions, and to distinguish working devices from artifact, statistical analysis must be performed on a large set of data. Different mechanisms for molecular rectification have been proposed, ${ }^{20}$ but to date, no mechanism has been proved with controls and statistical analysis of the sort we describe. $^{14,21}$ 


\section{Background}

The $\mathbf{A g}^{\mathrm{TS}}$-SAM//Ga $\mathrm{O}_{3} / \mathbf{E G a I n}$ Junctions. We have previously described

measurements of junctions of the form $\mathrm{Ag}^{\mathrm{TS}}$-SAM// $\mathrm{Ga}_{2} \mathrm{O}_{3} / \mathrm{EGaIn}$ (EGaIn, $75.5 \%$ Ga and $24.5 \%$ In by weight, $\mathrm{mp}=15.7^{\circ} \mathrm{C}$ and superficial layer of $\mathrm{Ga}_{2} \mathrm{O}_{3}$ ), incorporating SAMs of n-alkanethiolates ${ }^{22}$ and Fc-terminated alkanethiolates. ${ }^{23}$ Stable, reproducible molecular tunneling junctions can be fabricated using bottom-electrodes of $\mathrm{Ag}^{\mathrm{TS}}$ and topelectrodes of $\mathrm{Ga}_{2} \mathrm{O}_{3} / \mathrm{EGaIn}$ suspended from a syringe. ${ }^{22,23}$ Although this system still requires an experienced operator and substantial attention to detail, it can generate data with enough reproducibility to act as a sensitive probe of molecular structure. These molecular junctions are also stable to repeated measurement and to environmental perturbations (e.g. vibrations). These two traits - reproducibility and stability - make $\mathrm{Ag}^{\mathrm{TS}}$-SAM// $\mathrm{Ga}_{2} \mathrm{O}_{3} / \mathrm{EGaIn}$ junctions useful tools for performing physical-organic studies that measure the dependence of tunneling current on the composition and structure of the SAM, and on the electrical potential $(V)$ between the electrodes.

Possible Defects in the $\mathrm{Ag}^{\mathrm{TS}}-\mathrm{SC}_{\mathbf{1 1}} \mathbf{F c} / / \mathrm{Ga}_{2} \mathrm{O}_{3} / \mathbf{E G a I n}$ Junctions. The tunneling current $J\left(\mathrm{~A} / \mathrm{cm}^{2}\right)$ generally depends exponentially (for simple alkanethiolates) on the distance, $d(\AA)$, between the two electrodes. This relation can be approximated by a simple form of the Simmons equation (eq. 2, where $J_{0}\left(\mathrm{~A} / \mathrm{cm}^{2}\right)$ is the current density flowing through electrode-SAM interfaces in the hypothetical case of zero separation, and $\beta\left(\AA^{-1}\right)$ is the tunneling decay constant $) .{ }^{24}$ The measured tunneling current is sensitive to, or may even be dominated by, defects in the junctions that cause variations of the distance between the top- and bottom-electrodes. ${ }^{25}$

$$
J=J_{0} e^{-\beta d}
$$


Figure 2 shows several types of defects that may be present in the tunneling junctions. An ideal junction would have no defects in either electrode, and the SAM would be perfectly ordered (Fig. 2A). Because the Fc head groups have a diameter larger than that of the alkyl chains, $\mathrm{SAMs}$ of $\mathrm{SC}_{11} \mathrm{Fc}$ may have a structure suggested by that depicted in Fig. 2B, in which the Fc head groups adopt different orientations, and the alkyl groups are at least partially disordered (wet electrochemistry indicates some disorder, see below and Supplemental Information). Figs. 2C-H classify local defects as either "thin-area" or "thick-area", according to whether they decrease or increase the local separation $d$ between the electrodes. Because tunneling current decays exponentially with increasing inter-electrode spacing $d$ (eq. 2), thin-area defects cause a much greater deviation between the predicted and measured values of $J$ than thick-area defects. ${ }^{25}$ Thin-area defects lead to high observed values of $J$, and these anomalously high values of $J$ can dominate the observed transport of charge through a junction to a disproportionate extent, relative to their area. By contrast, thick-area defects decrease the observed value of $J$, but only in (approximately) direct proportion to their area.

The following five classes of defects lead to thin-area defects. ${ }^{26}$ i) The $\mathrm{Ag}^{\mathrm{TS}}$ surfaces have step edges and vacancy islands (Fig. 2C). ${ }^{27}$ ii) $\mathrm{The}^{\mathrm{Ag}}{ }^{\mathrm{TS}}$ surfaces have grains and grain boundaries (Fig. 2D). ${ }^{27}$ iii) The alkyl chains in SAMs of alkanethiolates have a tilt angle on silver of $\sim 11^{\circ}$ with respect to the surface normal. ${ }^{28}$ Divergence of alkyl chains at boundaries between domains in the SAM will cause disorder in the SAM (Fig. $2 \mathrm{E}){ }^{26}{ }^{26}$ iv) Material physisorbed at the metal electrode may locally prevent the adsorption of alkanethiols (Fig. 2G) ${ }^{26}$ v) Impurities within the metal film also may prevent the adsorption of the alkanethiolates or cause disorder in the SAM (Fig. 2F) ${ }^{26}$ 
Figure 2: Schematic representations of several possible defects in $\mathrm{Ag}^{\mathrm{TS}}-\mathrm{SC}_{11} \mathrm{Fc} / / \mathrm{Ga}_{2} \mathrm{O}_{3} / \mathrm{EGaIn}$ junctions. A) a defect-free junction, and defects due to $\mathrm{B}$ ) $\mathrm{Fc}$ moieties having different orientations, C) step-edges in the $\mathrm{Ag}^{\mathrm{TS}}$ electrode (similar defects are also caused by vacancy islands), D) grain boundaries of the $\mathrm{Ag}^{\mathrm{TS}}$ electrode, E) boundaries between domains in the SAM with different orientations of the alkyl chains, F) physisorbed material, G) impurities in the $\mathrm{Ag}^{\mathrm{TS}}$-electrode ( $\mathrm{F}$ and $\mathrm{G}$ may locally prevent adsorption of thiols), and $\mathrm{H}$ ) non-conformal contact of the $\mathrm{Ga}_{2} \mathrm{O}_{3} /$ EGaIn topelectrode with the SAM. 

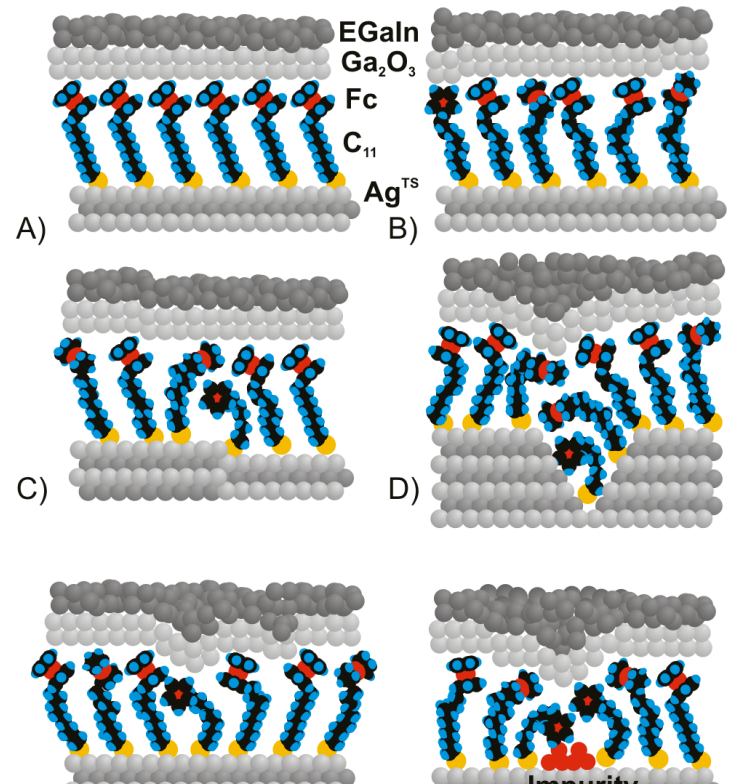

E)

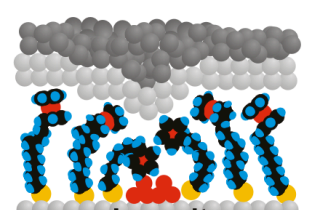

F) 800600 Impurity

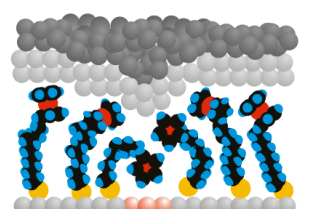

G) 6000 Impurity 000000

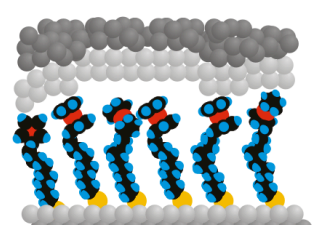

H) 64660606060606606060 
Two types of defects lead to thick area-defects. i) Different orientations in the Fc head groups may lead to more extended conformations of the $\mathrm{SC}_{11} \mathrm{Fc}$ molecule than other orientations (Fig. 2C). ii) The top-electrode of $\mathrm{Ga}_{2} \mathrm{O}_{3} / \mathrm{EGaIn}$ may not make conformal contact with the SAM (Fig. 2H) ${ }^{29}$ Also physisorbed large particles (e.g., dust) may cause thick area defects. Estimation of the actual area of the contact between the SAM and the $\mathrm{Ga}_{2} \mathrm{O}_{3} /$ EGaIn electrode remains a source of uncertainty in $J$ (supplemental information), but not in $R$. We form junctions with large areas $\left(100-500 \mu \mathrm{m}^{2}\right)$, and therefore probably encounter a distribution in the number of each type of defect in every junction.

The Importance of Statistical Analysis. The analysis of statistically large numbers of data is an absolute prerequisite to characterizing the resulting distributions in the values of $J$ and $R$ (as it is in all studies of charge transport through SAMs at this stage of development of this field). Importantly, rectification can also occur in molecular junctions from non-molecular effects, such as the incorporation of electrodes of different materials, ${ }^{4}$ dissimilarity in the contacts between the molecules and the bottom- and topelectrodes, the presence of metal oxides at the electrodes, ${ }^{30,31}$ or any other asymmetry in the junctions. Thus, systematic physical-organic studies with appropriate control experiments and statistically large numbers of data are a requirement to determine if any observed rectification is caused by the molecules inside the junctions, or by other effects having to do with the structure of non-molecular parts of the junctions.

The experimental values of $J$, as well as those of $R$, are not normally distributed, but lognormally distributed; hence, the most relevant statistic for describing the distribution of $R$ is not the mean (eq. 3, also called the arithmetic mean, with $\mathrm{N}$ is the number of values of $J$ ), which is biased towards high values of $J$, but the log-mean (eq. 4, also called the 
geometric mean). ${ }^{22,23,32,25}$

$$
\begin{gathered}
<J>=\frac{1}{N} \sum_{i=1}^{N} J_{i} \\
<J>_{\log }=10^{z} \text { with } z=\frac{1}{N} \sum_{i=1}^{N} \log _{10}\left|J_{i}\right|
\end{gathered}
$$

Other groups also observed log-normal distributions for the values of $J .^{14,15} \mathrm{To}$ explain this observation, we note that tunneling current depends exponentially on the distance $d$ between the top- and bottom-electrodes (eq. 2). In an ideal case, the value of $d$ is only determined by the thickness of the SAM. In real junctions, defects in the SAM and the electrodes (Fig. 2) result in thin- and thick-areas and lead to a (presumably) normal distribution of the value of $d$. A parameter, such as $J$, that depends exponentially on a normally distributed variable is itself log-normally distributed. The rectification ratio is determined using the ratio of $|J|$ at two opposing biases and is, for this reason, also lognormally distributed. In order to characterize the peak and spread of these distributions (in the values of $J$ and $R$ ) and to assess the yield of these junctions accurately, we analyzed large numbers $(\mathrm{N}=100-1000)$ of data.

\section{Theory of Molecular Rectification: Molecular Rectifier Based on Two}

Conductive Molecular Orbitals. In the early days of molecular electronics, Aviram and Ratner proposed that molecules containing electron donor (D) and acceptor (A) moieties separated by an insulating bridge (so-called D- $\sigma-\mathrm{A}$ compounds, Fig. $3 \mathrm{~A}$ ) would be good candidates for molecular rectification. ${ }^{3}$ The origin of rectification with these systems would involve charge transfer from one electrode to the acceptor, to the donor, and finally to the second electrode at forward bias $\left(V_{\mathrm{f}}(\mathrm{V})\right)$. At opposite bias (reverse bias, $V_{\mathrm{r}}$ (V)) charge would traverse the junction in the opposite sequence; this direction would 
require a larger potential to bring the energy levels of the donor and acceptor into favorable alignment. Hence, $V_{\mathrm{r}}>V_{\mathrm{f}}$ and the molecule would rectify. ${ }^{33}$

\section{Theory of Molecular Rectification: Molecular Rectifier Based on One}

Conductive Molecular Orbital. The molecular rectifier described in this paper, i.e., $\mathrm{SC}_{11} \mathrm{Fc}$, has a structure that is similar to that of the molecular rectifiers proposed by two groups: those of Williams ${ }^{1}$ and Baranger et al. ${ }^{2}$ (Fig. 3). We first briefly discuss these two strategies, in order to explore their assumptions and limitations of each, and to identify the minimum requirements for a successful molecular diode based on a single conducting molecular orbital.

The groups of Williams ${ }^{1}$ and Baranger et al. ${ }^{2}$ proposed that molecular tunneling junctions with a single conducting molecular orbital that is offset slightly in energy from the Fermi levels of the electrodes - either a HOMO or a LUMO - and asymmetrically coupled to one of the electrodes (i.e., in closer spatial proximity to one electrode than the other) can rectify. Figure 3B outlines the schematic structure of a molecule designed to cause an asymmetric drop in potential between electrodes, which, in turn, results in an asymmetric coupling of the conducting molecular orbital to the electrodes. These molecular rectifiers consist of three parts: i) connecting groups (i.e., thiols) to attach the molecules to the electrodes, ii) a conductive part (a phenyl or a cobaltocene (Co) moiety) with an energetically accessible LUMO or HOMO, and iii) insulating groups $\left(\mathrm{C}_{\mathrm{n}}\right.$ moieties, or alkyl chains) of different lengths to provide asymmetry. Figure 4 outlines the mechanisms for the molecular rectifiers proposed by Williams ${ }^{1}\left(\mathrm{SC}_{10}\right.$-phenyl- $\mathrm{C}_{2} \mathrm{~S}$, Fig. 3C) and Baranger et al. ${ }^{2}\left(\mathrm{SC}_{4} \mathrm{CoS}, \mathrm{Co}=\right.$ cobaltocene, Fig. 3D). These molecular rectifiers have a "conductive" HOMO or LUMO level that is i) centered at the Co, or 
phenyl moiety, respectively, ii) energetically positioned just above the Fermi levels of the electrodes (a small difference in energy between the Fermi levels of the electrodes and the conducting molecular level ensures that the molecular diode can operate at low bias), iii) asymmetrically coupled to each electrode via "insulating" alkyl spacer(s) of disparate lengths. The conductive molecular orbital follows the potential of the nearest electrode. Since the molecular orbital follows the potential of one of the electrodes, it can overlap with the Fermi levels of both electrodes, and thus participate in charge transport, more easily at one polarity of bias (Fig. 4A, forward bias, $V_{\mathrm{f}}(\mathrm{V})$ ) than the other (Fig. 4B, reverse bias, $\left.V_{\mathrm{r}}(\mathrm{V})\right)$. Hence, $V_{\mathrm{r}}>V_{\mathrm{f}}$ and rectification of currents is achieved.

Theory of Molecular Rectification: Requirements of the Molecular Diodes Based on One Conductive Molecular Orbital. If the molecular conducting orbital is wider than the energy difference between the Fermi levels of the electrodes and the energy level of the conducting molecular orbital, then the molecular diode would allow current to pass through the tunneling junctions in both directions of bias, i.e., the "leakage" current would be large. Bratkovsky et al. ${ }^{34}$ calculated the optimal width of the molecular conducting level to be $12 \mathrm{meV}$. According to their calculations, at room temperature broadening of the molecular level due to thermal energy $-k_{\mathrm{B}} T=26 \mathrm{meV}$ at room temperature with $T=$ temperature $(\mathrm{K})$ and $k_{\mathrm{B}}=$ the Boltzmann constant $(\mathrm{eV} / \mathrm{K})-$ will be significant and will lower the efficiency of the molecular diode. To localize the molecular orbital at the phenyl moiety, Williams et al. ${ }^{1}$ introduced a short alkyl spacer $\left(\mathrm{C}_{2}, L_{2}\right)$ to prevent hybridization of the LUMO level of the phenyl moiety with the sulfur that covalently bonds to the electrode (Fig. 3C). 
Figure 3: Several proposed molecular diodes. Aviram and Ratner proposed molecular diodes that contain electron donor and acceptor groups (A). Another class of proposed molecular diode has a single molecular level (HOMO or LUMO) asymmetrically separated from the electrodes by two insulating groups of different length (B). Williams et al. ${ }^{1}$ proposed a molecular rectifier with an asymmetrically coupled LUMO level (C), while Baranger et al. ${ }^{2}$ proposed a rectifier with an asymmetrically coupled HOMO level (D). The latter is similar to the molecular rectifier that is used in the present study (E).. Metzger et al. experimentally investigated a proposed molecular diode (F) consisting of a donor $(\mathrm{Fc})$ - alkyl bridge $(\sigma)$ - acceptor (perylene) and functionalized with long alkyl chains $\left(\mathrm{C}_{19}\right)$. 


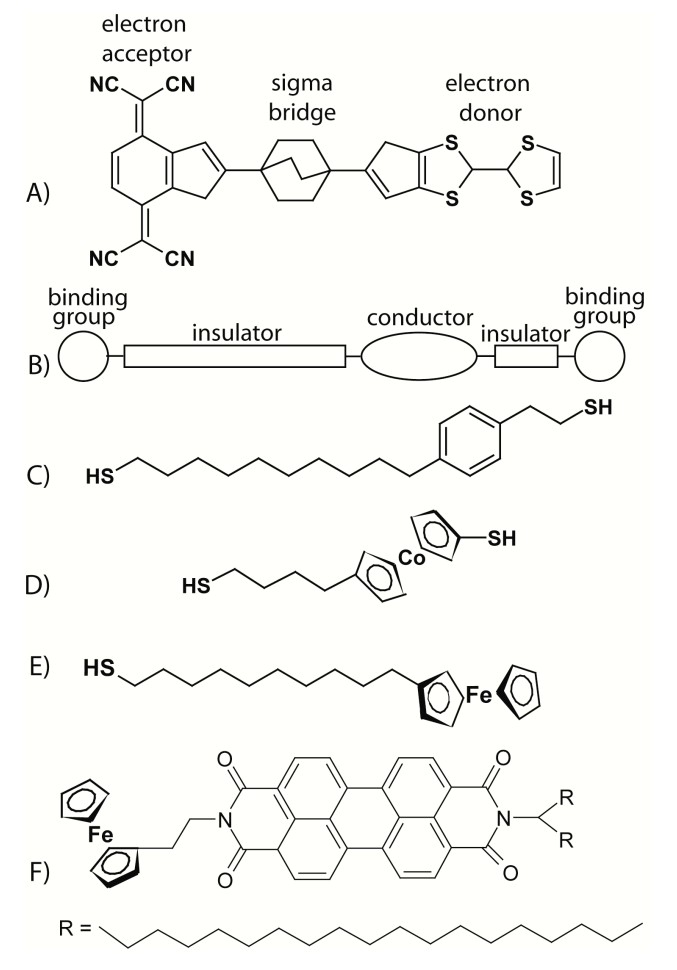


Figure 4: The mechanisms of rectification proposed by Williams ${ }^{1}$ (A and B) and Baranger et al. ${ }^{2}$ (C and D). The junction consists of two electrodes that contact the molecular diode (i.e., $\mathrm{SC}_{10}$-phenyl- $\mathrm{C}_{2} \mathrm{~S}($ Fig. $3 \mathrm{~B})$ or $\mathrm{SC}_{4} \mathrm{CoS}(\mathrm{Co}=$ cobaltocene, Fig. 3C)), with its LUMO or HOMO level energetically located just above the Fermi levels of the electrodes. The Fermi levels of the electrodes are equal. The width of the junction is determined by the length of the molecule. The spatial position of the LUMO is determined by the relative lengths of the alkyl spacers, i.e., $L_{1}$ and $L_{2}$ (for $\mathrm{SC}_{10}$-phenyl$\mathrm{C}_{2} \mathrm{~S} L_{1}=\mathrm{C}_{10}$ and $L_{2}=\mathrm{C}_{2}$, for $\mathrm{SC}_{4} \operatorname{CoS} L_{1}=\mathrm{C}_{4}$ and $L_{2}$ is zero). A) and C) depict operation at forward bias: the current rises when the Fermi levels align with the conducting molecular level (at $V=\mathrm{V}_{\mathrm{f}}$ ). B) and D) depict operation at reverse bias and show that greater bias is necessary than at forward bias, in order to align the Fermi levels with the conducting molecular orbital. Ford et al. ${ }^{35}$ analyzed a general two-barrier system $(\mathrm{F})$ to calculate the values for $R$ as a function of barrier widths $\left(d_{1}\right.$ and $\left.d_{2}\right)$ and heights $\left(U_{1}\right.$ and $\left.U_{2}\right)$. F) shows this barrier for $d_{2} / d_{1}=1$ and $U_{2} / U_{1}=0.5$. 


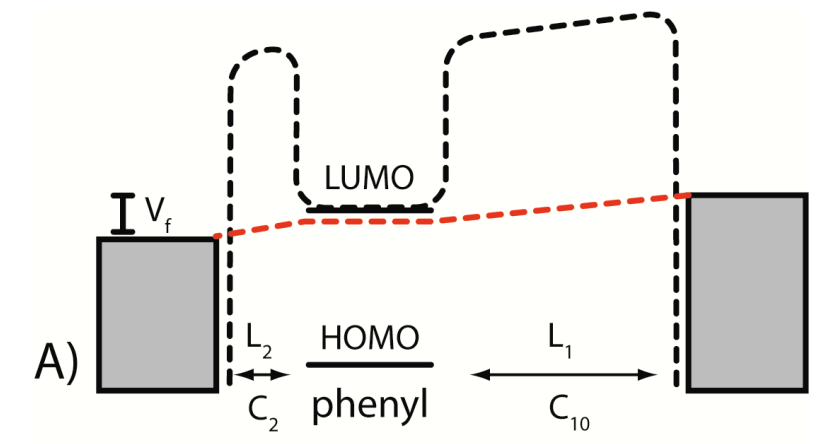

B)
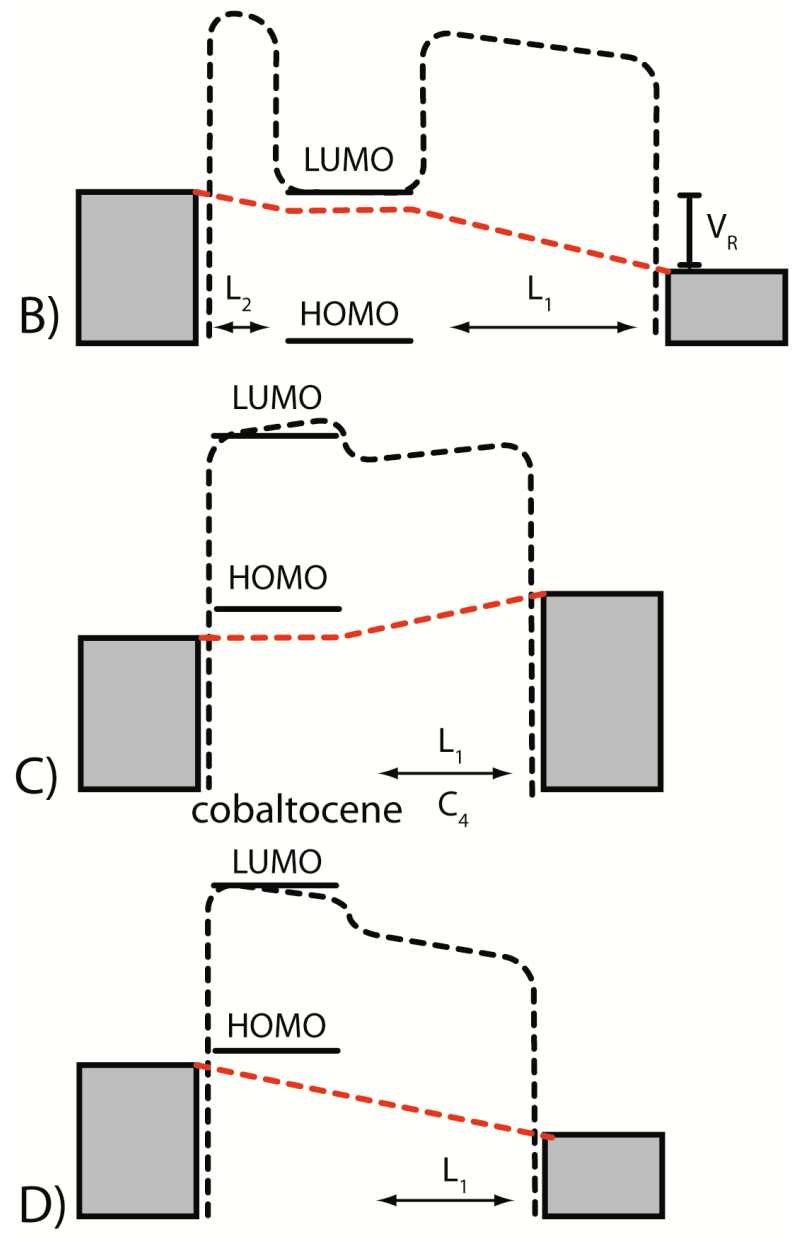

Double barrier junction

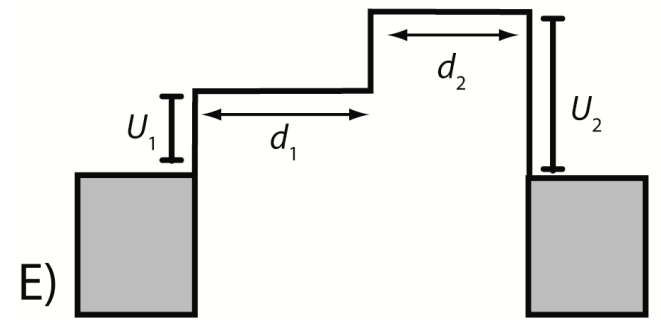


Williams et al. ${ }^{1}$ assumed that the potential drop across the conducting part, i.e., the phenyl, of their molecular rectifier, $\mathrm{SC}_{10}$-phenyl- $\mathrm{C}_{2} \mathrm{~S}$ (Fig. $3 \mathrm{C}$ ), is insignificant at any bias, because the $\pi$-bonds are more easily polarized than $\sigma$-bonds and that the barrier heights of both alkyl spacers are equal. Figure 4 shows the shape of the tunneling barrier and the potential drop across this barrier defined by the conductive and insulating part of $\mathrm{SC}_{10}$-phenyl- $\mathrm{C}_{2} \mathrm{~S}$. They calculated that the larger the ratio of the long and the short alkyl spacers, $L_{1} / L_{2}$ (which, in turn, is proportional to the ratio of the potential drops along these alkyl spacers), the larger the rectification ratio would be. The resistance of the tunneling junction, however, increases exponentially with the total length of the alkyl spacers, $L_{1}+L_{2}$. A molecular diode with alkyl spacers of ten carbon atoms for $L_{1}$ and two carbons for $L_{2}$, i.e., the molecular rectifier depicted in Figure 3C, would yield rectifiers that are not too resistive and would have large rectification ratios $(\sim 35){ }^{1}$

Baranger et al. ${ }^{2}$ calculated that the potential drop across the conducting part, i.e., the Co moiety, of their molecular rectifier, $\mathrm{SC}_{4} \mathrm{CoS}$ (Fig. 3D), is significant whenever the rectifier is not under forward bias. They calculated the potential drop along the $\mathrm{SC}_{4} \mathrm{CoS}$ rectifier (Fig. 3D) and found that when the HOMO does not overlap with the Fermi levels of the electrodes, the potential drops more or less uniformly along the whole length of the molecule, including both the $\mathrm{C}_{4}$ alkyl spacer and the Co moiety (Fig. 4C). In contrast, when the HOMO does overlap with the Fermi levels of the electrodes, the potential drops primarily along the $\mathrm{C}_{4}$ alkyl chain, and almost no potential drops along the Co (Fig. 4D). Baranger et al. ${ }^{2}$ left out a short alkyl spacer between Co and the thiolate binding group (or $L_{2}$, using the nomenclature by Williams et al. ${ }^{1}$ ), and connected the thiolate binding group directly to the Co moiety, to ensure a molecular diode with high conductivity. They 
calculated that this molecular diode would have a rectification ratio of $R=10$.

The molecular diode suggested by Baranger et al. ${ }^{2}$ is essentially a double-barrier junction (which becomes a single-barrier junction at forward bias). The conductive and insulating parts of the molecule define the barrier heights and widths. Ford et al. ${ }^{35}$ calculated the rectification ratios of double-barrier tunneling junctions as a function of both the relative barrier widths and heights. They did not distinguish between conductive and insulating portions of the barrier. Figure 4D shows this double-barrier system with the widths, $d_{1}$ and $d_{2}$, and heights, $U_{1}$ and $U_{2}$, of both barriers indicated. They concluded that double-barrier will give the largest values of $R$ of $\sim 22$ for values of $0.1<U_{2} / U_{1}<1$ and $d_{2} / d_{1} \approx 1$; the value of $R$ is small $(<10)$ when $U_{2} / U_{1}>1$ or large $(>40)$ when $U_{2} / U_{1}<$ 0.1 (but these conditions require unrealistically extreme ratios of the barrier heights).

These studies, as a group, indicate that molecular diodes based on asymmetry benefit from four conditions (although not all four are required for rectification). If two tunneling barriers are present, i) the ratio of the widths of the tunneling barriers should be $d_{2} / d_{1} \approx$ $0.5-1$, but the total width should not exceed $2-3 \mathrm{~nm}$, and ii) the ratio of the heights of the tunneling barriers $U_{2} / U_{1}$ must be $0.1<U_{2} / U_{1}<1$. If the diode incorporates a conductive molecular orbital, iii) this HOMO or LUMO must be energetically narrow (the broadening of the orbital must at least be less than the difference in energy between the Femi levels of the electrodes and the conducting molecular orbital and, ideally, less than $12 \mathrm{meV}$ ), and iv) the energy difference between the HOMO or LUMO level and the Fermi levels of the electrodes should be small (less than $0.5 \mathrm{eV}$ ).

Theoretical Limitations of Molecular Rectifiers. These theoretical results suggest that molecular rectifiers based on one conductive molecular orbital or, more generally, 
based on an asymmetric double-barrier, cannot achieve rectification ratios exceeding $\sim 22 .{ }^{35}$ Stadler et al. ${ }^{36}$ performed calculations on different types of molecular diodes, including of the type of D- $\sigma-\mathrm{A}$ proposed by Ratner and Aviram, and concluded that, in general, molecular diodes operating in the tunneling regime cannot have rectification ratios larger than $\sim 20$. These theoretical upper bounds for the rectification ratios of molecular diodes are far lower than the values routinely achieved with semiconductor diodes $\left(\mathrm{R}=10^{6}-10^{8}\right)$, but still higher than the small values actually observed for many molecular rectifiers $(R=1-10)$.

These theoretical studies as a group have only performed calculations on molecular diodes in the tunneling regime. Thus, other mechanisms of charge transport - hopping may be important, especially at room temperature - have not been considered. Stadler et al. ${ }^{36}$ proposed that molecular diodes with more complex mechanisms of charge transport are required to achieve rectification ratios larger than $\sim 20$.

Examples of Rectifying Junctions. By far the most studied of the types of candidates for molecular rectification are the donor-bridge-acceptor compounds of the kind proposed by Aviram and Ratner (Fig. 3A). Though many investigators have reported rectification using this class of compounds, ${ }^{4,13,43,48,41}$ the mechanism of rectification remains obscure for five reasons. i) These junctions have often incorporated electrodes of different materials, but analysis of them has not considered the difference of electrode materials as a source of rectification. ${ }^{37,38}$ ii) For the mechanism of Aviram and Ratner to be valid, both the LUMO and HOMO levels of the donor and acceptor moieties must be energetically accessible to the Fermi levels of both electrodes ${ }^{3}-$ i.e., at the bias where rectification occurs, the Fermi level of the electrode adjacent to the LUMO must lie 
below the LUMO while that of the electrode adjacent to the HOMO must lie above the HOMO. Most compounds that have been studied do not meet this condition because they have large HOMO-LUMO gaps, or because the HOMO and LUMO lie too far above or below the Fermi levels of the electrodes to be able to overlap energetically in the range of potentials applied..$^{39,40,44}$ iii) Most studies have generated top-electrodes by depositing gold or titanium (using electron-beam evaporation or sputtering) onto monolayers of reactive organic molecules. ${ }^{16,44}$ It is unlikely that the molecules are not destroyed, or that the monolayer is not penetrated by the highly energetic incoming metal atoms or clusters of atoms. ${ }^{16}$ iv) Asymmetric placement of the donor-acceptor moiety inside the junctions may cause rectification that is not inherent to the donor-acceptor design. Many studies involve monolayers formed by the Langmuir-Blodgett technique that requires amphiphilic molecules, in which one side of the polar D- $\sigma-\mathrm{A}$ moiety is functionalized with long alkyl tails. The result is that the donor-bridge-acceptor part of the molecule is positioned asymmetrically inside the junction. ${ }^{41,42,43,44}$ Figure $3 \mathrm{~F}$ shows an example of such a molecular rectifier reported by Metzger et al. ${ }^{44}$ Thus, these experiments fail to identify the mechanism of rectification because they cannot distinguish between that described by Williams ${ }^{1}$ and Baranger, ${ }^{2}$ involving asymmetric potential drops and a single molecular orbital, and that described by Aviram and Ratner, involving two molecular orbitals. ${ }^{3}$ Other factors that may complicate the potential landscape of these junctions include the presence of ions in the junction and incomplete localization of the HOMO and LUMO levels. ${ }^{31,45,46}$ v) Most examples report rectification ratios that are small (less than 10) and do not describe systematic studies of the relationship between molecular structure and rectification. ${ }^{47}$ Because the electrodes and interfaces in SAM-based 
junctions are never precisely characterized, it is very difficult to prove that small rectification ratios are caused by molecules inside the junctions, and not by asymmetries in the electrodes or interfaces.

Ashwell et al. ${ }^{48}$ report high rectification ratios (up to 3000) for complex molecular architectures (a layered structure of a donor-acceptor compound with one long alkyl chain with on top a layer of phthalocyanine: bis-[ $N$-(10-decyl)-5-(4-dimethylamino benzylidene)-5,6,7,8-tetrahydroisoquinolinium]-disulfide diiodide and metathesis with the tetrasodium salt of copper(II) phthalocyanine-3,4',4",4"' '-tetrasulfonate) measured by scanning tunneling microscopy (STM). Although the rectification ratio is high in these systems, its origin is difficult to determine for four reasons. i) The potential drops in these junctions are unknown. The vacuum gap between the SAM and the STM-tip, and the presence of counter-ions in these junctions, will influence the potential drops. ii) Virtually no structural information is available for monolayers of this structural complexity; therefore, the spatial alignment of the donor-bridge-acceptor structure is unconfirmed and may be incommensurate with that required by the Ratner-Aviram mechanism. iii) The HOMO and LUMO are spatially asymmetrically located inside this tunneling junction; this asymmetry may already be a cause of rectification. iv) Yields and statistical analysis have not been reported (only one example is given).

$\mathrm{SC}_{11} \mathrm{Fc}$-Based Tunneling Junctions. Zandvliet et al. ${ }^{49}$ inserted $\mathrm{SC}_{11} \mathrm{Fc}$ in monolayers of $\mathrm{SC}_{11} \mathrm{CH}_{3}$ on $\mathrm{Au}$ and formed STM tunneling junctions with a tungsten STM tip. The $I(\mathrm{~V})$ characteristics measured with $\mathrm{SC}_{11} \mathrm{Fc}$ in the junctions rectified currents with rectification ratios of $5-10$, while those measured on $\mathrm{SC}_{11} \mathrm{CH}_{3}$ did not rectify currents. This important control experiment establishes the necessity of the Fc 
moiety for rectification in these junctions. Similarly, we showed that junctions of the type $\mathrm{Ag}^{\mathrm{TS}}-\mathrm{SC}_{11} \mathrm{Fc} / / \mathrm{Ga}_{2} \mathrm{O}_{3} / \mathrm{EGaIn}$ and $\mathrm{Ag}^{\mathrm{TS}}-\mathrm{SC}_{11} \mathrm{Fc} / / \mathrm{Au}^{\mathrm{TS}}$ rectify currents with rectification ratios of $\sim 100$, whereas junctions of the form $\mathrm{Ag}^{\mathrm{TS}}-\mathrm{SC}_{\mathrm{n}-1} \mathrm{CH}_{3} / / \mathrm{Ga}_{2} \mathrm{O}_{3} / \mathrm{EGaIn}$ $(n=10,14)$ have very low rectification ratios $(R=1-5) .{ }^{23}$ Thus, the rectification of currents by $\mathrm{SC}_{11} \mathrm{Fc}$ has been observed in three different types of tunneling junctions and we believe, therefore, that the rectification observed in these junctions is caused by the chemical composition of the junctions, and not by any other asymmetry.

McCreery et al. ${ }^{30}$ reported large rectification ratios ( $R$ up to $\sim 600$ ) for junctions that have redox-active monolayers and redox-active $\mathrm{TiO}_{2}$ top-electrodes. The mechanism of rectification in these junctions involves redox-reactions between the monolayer and the top-electrode. ${ }^{50}$ In junctions of $\mathrm{Ag}^{\mathrm{TS}}-\mathrm{SC}_{11} \mathrm{Fc} / / \mathrm{Au}^{\mathrm{TS}}$ the top-electrode is redox-inactive, but the junctions still rectify currents. Thus, the mechanism of rectification in these junctions does not involve redox reactions between the SAM and the top-electrode, but is due to the molecular properties of the SAM.

\section{Nomenclature}

See the supplemental information for a detailed description of the nomenclature.

\section{Experimental Design}

Choice of the Bottom-Electrode. Substrates of $\mathrm{Ag}^{\mathrm{TS}}$ supported the SAMs and served as bottom-electrodes. ${ }^{25}$ The $\mathrm{Ag}^{\mathrm{TS}}$ electrodes have a lower surface roughness (root-meansquare roughness $=1.2 \pm 0.1 \mathrm{~nm}$ measured over an area of $25 \mu \mathrm{m}^{2}$ ) than substrates used as-deposited by e-beam evaporation (AS-DEP, root-mean-square roughness $=5.2 \pm 0.4$ 
$\mathrm{nm}$ measured over an area of $\left.25 \mu \mathrm{m}^{2}\right) .{ }^{25}$ The maximum grain size was $\sim 1 \mu \mathrm{m}^{2}$ for the $\mathrm{Ag}^{\mathrm{TS}}$ surface and $\sim 0.0064 \mu \mathrm{m}^{2}$ for the AS-DEP surface. ${ }^{25}$ The smoothness and large grain sizes of $\mathrm{Ag}^{\mathrm{TS}}$ surfaces reduce the number of defects in SAMs supported on $\mathrm{Ag}^{\mathrm{TS}}$ surfaces, relative to AS-DEP surfaces.

Choice of the Top-Electrode. The EGaIn has a superficial layer of oxides of gallium, likely $\mathrm{Ga}_{2} \mathrm{O}_{3} .{ }^{51}$ The formation of the film of $\mathrm{Ga}_{2} \mathrm{O}_{3}$ is a self-limiting process, and we believe that the thickness is limited to only a few atomic layers. The thin layer of $\mathrm{Ga}_{2} \mathrm{O}_{3}$ is responsible for the apparent non-Newtonian properties of the liquid $\mathrm{Ga}_{2} \mathrm{O}_{3} /$ EGaIn. $^{52}$

These properties allow $\mathrm{Ga}_{2} \mathrm{O}_{3} / \mathrm{EGaIn}$ to form stable, non-equilibrium shapes (e.g. cones) at the microscale. Conically shaped $\mathrm{Ga}_{2} \mathrm{O}_{3} / \mathrm{EGaIn}$ tips are easy to use as topelectrodes to form SAM-based junctions. ${ }^{22}$ Unlike $\mathrm{Hg}, \mathrm{Ga}_{2} \mathrm{O}_{3} / \mathrm{EGaIn}$ i) does not alloy on contact with the $\mathrm{Ag}^{\mathrm{TS}}$ bottom-electrode, ii) is stable towards vibrations, iii) does not require stabilization in a bath of hydrophobic solvent, and iv) apparently does not penetrate the SAM and thus gives high yields (70-90\%) of non-shorting junctions that are stable for at least $20 J(V)$ traces $(1$ trace $\equiv 0 \mathrm{~V} \rightarrow 1 \mathrm{~V} \rightarrow-1 \mathrm{~V} \rightarrow 0 \mathrm{~V}$; at best, $25 \%$ of Hgdrop based junctions survive beyond the first trace). In addition, $\mathrm{Ga}_{2} \mathrm{O}_{3} / \mathrm{EGaIn}$-based junctions make it possible to measure charge transport across single SAMs (a single monolayer on the bottom-electrode), ${ }^{22,23}$ while Hg-drop junctions only allow measurements across double monolayers (a monolayer on both the bottom-electrode and on the $\mathrm{Hg}$ top-electrode are required to obtain stable, non-shorting junctions). ${ }^{25,53,54}$

We found that the shape and surface roughness of the cone-shaped tips depend on the operator. ${ }^{55}$ These variations of the cone-shape tips introduce ambiguities in the 
measurement of current density. An experienced operator with attention to detail, however, can generate reliable sets of data.

The use of $\mathrm{Ga}_{2} \mathrm{O}_{3} / \mathrm{EGaIn}$ to form top-electrodes introduces five ambiguities in the measurement of $J(\mathrm{~V})$. i) The resistivity of the layer of $\mathrm{Ga}_{2} \mathrm{O}_{3}$ or its effect on the $J(\mathrm{~V})$ characteristics is uncertain. $\mathrm{Ga}_{2} \mathrm{O}_{3}$ is a semiconductor, and its resistance depends on the method of formation and varies from 1 to $>10^{6} \Omega \mathrm{cm} .{ }^{56}$ We estimated the resistance of the layer of $\mathrm{Ga}_{2} \mathrm{O}_{3}$ directly with two different methods (see Supplemental Information) and found that this layer is a factor of 65 more resistive than the bulk EGaIn, but at least four orders of magnitude less resistive than $\mathrm{SAMs}$ of $\mathrm{SC}_{10} \mathrm{CH}_{3} .{ }^{23,32}$ ii) The exact thickness of the layer of $\mathrm{Ga}_{2} \mathrm{O}_{3}$ is uncertain. We estimated the thickness of this layer of $\mathrm{Ga}_{2} \mathrm{O}_{3}$ on cone-shaped tips $\mathrm{Ga}_{2} \mathrm{O}_{3} / \mathrm{EGaIn}$ to be $1-2 \mathrm{~nm}$ with angle-resolved X-ray photoelectron spectroscopy (ARXPS) and time-of-flight secondary-ion mass spectroscopy (ToF SIMS) ${ }^{57}$ iii) The exact nature of the interface between the SAM and the layer of $\mathrm{Ga}_{2} \mathrm{O}_{3}$ is uncertain. We believe that that both the $\mathrm{CH}_{3}$ - and $\mathrm{Fc}$-terminated SAMs form van der Waals contacts with the $\mathrm{Ga}_{2} \mathrm{O}_{3}$. iv) The influence of physisorbed organic material on the surface of the $\mathrm{Ga}_{2} \mathrm{O}_{3}$ on the $J(\mathrm{~V})$ characteristics is uncertain. ARXPS and ToF SIMS indicate the presence this layer (with estimated of the thickness $(\sim 1 \mathrm{~nm})^{57}$ which thickness and/or composition most likely depends on the ambient conditions. v) The exact surface roughness of the layer of $\mathrm{Ga}_{2} \mathrm{O}_{3}$ is uncertain. We estimated the surface roughness of the cone-shaped tips by scanning electron microscopy (SEM) and optical microscopy and we concluded that the real contact area is $\sim 25 \%$ of the measured contact area (see Supplemental Information). ${ }^{29}$ Uncertainty in estimating contact area should, in principle, have the same effect on the total value of $J$ as an unknown number of thick- 
area defects in the junction. As discussed above, thick-area defects have a limited effect on the value of $J$ transport, compared to thin-area defects; therefore, variations in the cone-shaped tips are likely not the largest source of error in these measurements. This conclusion is confirmed by measurements of charge transport in SAM-based junctions where the $\mathrm{Ga}_{2} \mathrm{O}_{3} / \mathrm{EGaIn}$ electrode was applied by flowing EGaIn over a SAM through a microfluidic channel. ${ }^{32}$ This technique for applying the top-electrode eliminates much of the operator-dependence involved in forming conical tips of $\mathrm{Ga}_{2} \mathrm{O}_{3} / \mathrm{EGaIn}$, yet the error in $J$ using these microfluidic junctions was roughly the same as the error in $J$ using coneshaped tips. ${ }^{32}$ In any case, because rectification is the ratio of two opposing currents through the exact same junction, values of rectification essentially incorporate an internal standard (see below) and, thereby, reduce the contributions of all four of these factors.

Choice of the Molecular Rectifiers. The $\mathrm{Fc}_{\mathrm{c}}$-and $\mathrm{Fc}_{2}$-terminated $\mathrm{SAMs}$ are synthetically readily accessible, ${ }^{58,59}$ are electrochemically and structurally wellcharacterized, ${ }^{60,61}$ and have stable redox-active groups. ${ }^{62,63}$ These characteristics make it possible to study $J(\mathrm{~V})$ relationships as a function of the structure of the SAM.

We have shown that $\mathrm{SAMs}$ of $\mathrm{SC}_{11} \mathrm{Fc}$ are good molecular rectifiers in junctions of the type $\mathrm{Ag}^{\mathrm{TS}}-\mathrm{SC}_{11} \mathrm{Fc} / / \mathrm{Ga}_{2} \mathrm{O}_{3} / \mathrm{EGaIn}$, with a log-mean rectification ratio of $1.0 \times 10^{2}$ and a log-standard deviation of 3.0 ( $R$ is log-normally distributed, see below) ${ }^{23}$ This rectification ratio is sufficiently large and reproducible to enable physical-organic studies.

The structure of the molecular rectifier in these junctions resembles that of the molecular rectifiers proposed by Baranger et al. ${ }^{2}$ and Williams et al. ${ }^{1}$ (Fig. 3), i.e., the thiol is the "binding group", the $\mathrm{C}_{11}$ is the "insulator $\left(L_{1}\right)$ ", and the $\mathrm{Fc}$ is the "conductor" and is in direct contact with the top-electrode. The potential drops primarily along the $\mathrm{C}_{11}$ 
"insulator", and the HOMO level of the Fc group forms a van der Waals contact with the top-electrode (see below) and, thus, couples strongly to the top-electrode. Williams et al. ${ }^{1}$ argue that a short alkyl spacer $\left(L_{2}\right)$, to ensure narrow molecular resonances, is not required $\left(L_{2}=0\right)$ when the SAM forms a van der Waals contact with the top-electrode. Our molecular rectifier can also be described, at biases where the HOMO of Fc does not fall between the Fermi levels of the electrodes (see below), as a double-barrier junction of the type described by Ford et al, ${ }^{35}$ with the barrier widths and height defined by the alkyl and Fc moieties (Fig. 4D).

The large values of $R$ in our junctions, combined with the stability of $\mathrm{SC}_{11} \mathrm{Fc}$ and the synthetic accessibility of its derivatives, make this molecular rectifier a good platform for performing physical-organic studies and testing theory. $\mathrm{SC}_{11} \mathrm{Fc}$ fulfills the four requirements (indentified by theory; see above for more details) for being a good molecular rectifier. i) The ratio of the widths of the tunneling barriers is $d_{2} / d_{1} \approx 0.5$ (with $d_{2}=$ the length of the Fc moiety and $d_{1}=$ the length of the $\mathrm{C}_{11}$ ). ii) The ratio of the heights of the tunneling barriers $U_{2} / U_{1} \approx 0.2$ (with $U_{2}=$ the barrier height defined by the LUMO of the Fc moiety and $U_{1}=$ the barrier height defined by the LUMO of the $\mathrm{C}_{11}$ moiety). iii) The conductive molecular orbital, i.e., the HOMO centered at the Fc moiety, is narrow (or at least smaller than the energy difference of the HOMO level and the Fermi levels of the electrodes) due to the presence of a van der Waals gap between the Fc moiety and the top-electrode. iv) The energy difference between HOMO level and the Fermi levels of the electrodes is $<0.5 \mathrm{eV}$ (see below).

Table 1 shows the predicted rectification ratios for the SAMs used in this study by the models of Ford et al. ${ }^{35}$ as a function of $d_{2} / d_{1}$ and $U_{2} / U_{1}$, and Williams et al. ${ }^{1}$ as a function 
of $L_{1} / L_{2}$. The molecular properties of the SAMs determine the parameters of $d_{2} / d_{1}, U_{2} / U_{1}$, and $L_{1} / L_{2}$. To ascertain whether these molecules rectify currents by one of the mechanisms proposed by Baranger ${ }^{2}$, Ford ${ }^{35}$, and Williams et al. ${ }^{1}$, or, perhaps a combination thereof, we performed four sets of experiments. i) We varied the length of the insulator in the $\mathrm{SAMs}$ of $\mathrm{SC}_{11} \mathrm{Fc}$ from $\mathrm{C}_{11}$ to $\mathrm{C}_{9}$. According to the calculations of Williams, this change in linker length, and, thus, in the relative potential drops inside the junctions, should lower the value of $R$. The model of Ford, however, predicts a higher value of $R$ for $\mathrm{SAMs}_{\mathrm{S}} \mathrm{SC}_{9} \mathrm{Fc}$ than for $\mathrm{SC}_{11} \mathrm{Fc}$. ii) We changed the length of the conductor in the SAMs of $\mathrm{SC}_{11} \mathrm{Fc}$. Replacing the $\mathrm{Fc}$ moiety by a $\mathrm{Fc}_{2}$ moiety doubles the length of the conductive part of the SAM, while keeping other structural changes to the SAM, such as changes to the barrier heights, to a minimum. Ford et al..$^{35}$ calculated that this change in the barrier widths would result in an increase of the value of $R$, while the model of Williams et al. ${ }^{1}$ ignores the potential drop across the conductive part of the molecule and, thus, predict no change in the value of $R$. iii) We placed the conductor in the middle of the SAM $\left(L_{1}=L_{2}\right)$; these SAMs should not rectify according to either model. iv) We formed junctions with SAMs that do not contain a conducting part. These junctions consist of a single tunneling barrier and should not rectify.

Junctions in which the $\mathrm{Fc}$ moiety is absent (i.e., $\mathrm{Ag}^{\mathrm{TS}}-\mathrm{SC}_{10} \mathrm{CH}_{3} / / \mathrm{Ga}_{2} \mathrm{O}_{3} / \mathrm{EGaIn}$ ), and junctions in which the Fc moiety has been replaced by an alkyl chain of similar length (i.e., $\mathrm{Ag}^{\mathrm{TS}}-\mathrm{SC}_{14} \mathrm{CH}_{3} / / \mathrm{Ga}_{2} \mathrm{O}_{3} / \mathrm{EGaIn}$ ), are good controls. These controls establish the importance of the $\mathrm{Fc}$ moiety in molecular rectification, and rule out any other asymmetries of the junctions as being responsible for the large rectification. 
Table 1: Predicted and Measured Values of $R$ as a Function of the Chemical Composition of the SAMs.

Ford et al.

Williams et al.

Present work

\begin{tabular}{|c|c|c|c|c|c|c|}
\hline Type of SAM & $d_{2} / d_{1}{ }^{a}$ & $U_{2} / U_{1}^{\mathrm{b}}$ & $\begin{array}{l}\text { Predicted } \\
\text { value of } \boldsymbol{R}^{c}\end{array}$ & $L_{1} / L_{2}^{d}$ & $\begin{array}{l}\text { Predicted } \\
\text { value of } R^{\text {e }}\end{array}$ & $\begin{array}{l}\text { Measured values } \\
\text { of } R^{\mathrm{f}}\end{array}$ \\
\hline $\mathrm{SC}_{10} \mathrm{CH}_{3}$ & 1 & 1 & 1 & - & 1 & $1.5(1.4)$ \\
\hline $\mathrm{SC}_{14} \mathrm{CH}_{3}$ & 1 & 1 & 1 & - & 1 & $2.1(2.5)$ \\
\hline $\mathrm{SC}_{9} \mathrm{Fc}$ & $\sim 0.7$ & $\sim 0.2$ & $\sim 9$ & 9 & $\sim 20$ & $10(6.8)$ \\
\hline $\mathrm{SC}_{11} \mathrm{Fc}$ & $\sim 0.5$ & $\sim 0.2$ & $\sim 3$ & 11 & $\sim 40$ & $1.0 \times 10^{2}(3.0)$ \\
\hline $\mathrm{SC}_{11} \mathrm{Fc}_{2}$ & $\sim 1$ & $\sim 0.2$ & $\sim 20$ & 11 & $\sim 40$ & $5.0 \times 10^{2}(3.5)$ \\
\hline $\mathrm{SC}_{6} \mathrm{FcC}_{5} \mathrm{CH}_{3}$ & - & - & - & 1 & 1 & $1.2(1.7)$ \\
\hline
\end{tabular}

${ }^{\mathrm{a}}$ The widths of the tunneling barriers are defined by the lengths of the alkyl chains $\left(0.125 \mathrm{~nm} / \mathrm{CH}_{2}\right)^{25}$ and Fc moiety $(0.67 \mathrm{~nm}){ }^{64}$

${ }^{\mathrm{b}}$ The barrier heights are determined by the LUMO levels of the alkyl chains $(-2.6 \mathrm{eV})$ and Fc $(-0.4 \mathrm{eV})$; see text for details.

${ }^{\mathrm{c}}$ These values of $R$ are estimated from reference 35 .

${ }^{\mathrm{d}}$ Instead of a short alkyl chain $L_{2}$, we have a van der Waals gap. To estimate the $L_{1} / \mathrm{L}_{2}$ ratio, we used $L_{2}=1$ $\mathrm{CH}_{2}$ as a first order approximation (see text for details).

${ }^{\mathrm{e}}$ These values of $R$ are estimated from reference 1 .

${ }^{\mathrm{f}}$ Since rectification occurs in these two systems at opposite polarity, we define rectification ratio in junctions containing n-alkanethiolates and $\mathrm{SC}_{6} \mathrm{FcC}_{5} \mathrm{CH}_{3}$ as $R=|J(\mathrm{~V})| /|J(-\mathrm{V})|$, and for junction containing $\mathrm{Fc}_{\mathrm{c}}$ or $\mathrm{Fc}_{2}$ terminated SAMs as $R=|J(-\mathrm{V})| /|J(\mathrm{~V})|$. The number between parentheses is the log-standard deviation $\left(\sigma_{\log }\right)$. 
Table 1 does not include predictions of the model proposed by Baranger et al. ${ }^{2}$; they only calculated the rectifying properties of one molecule. The main difference between the model of Baranger et al. ${ }^{2}$ and Williams et al. ${ }^{1}$ is that Baranger assumes that the potential drop along the conductive part of the molecule is important when the conductive part does not participate in charge transport, while Williams et al. assumes that the change in potential drop across the conductor is not important. Examination of the values of $J$ obtained with junctions incorporating $\mathrm{SAMs}$ of $\mathrm{SC}_{14} \mathrm{CH}_{3}$ and $\mathrm{SC}_{11} \mathrm{Fc}$ should reveal whether the potential drops significantly along the conductive part of the molecule when the HOMO does not overlap with the Fermi levels of the electrodes. This examination will make it possible to determine which of the two models proposed by Williams et al. and Baranger et al. ${ }^{2}$ is more accurate.

\section{Experimental}

The experimental details are described in the supplemental information.

\section{Results and Discussion}

Wet Electrochemistry. We characterized the redox-active SAMs on $\mathrm{Au}^{\mathrm{TS}}$ surfaces with cyclic voltammetry using aqueous $1 \mathrm{M} \mathrm{HClO}_{4}$ solution as electrolyte, $\mathrm{Ag} / \mathrm{AgCl}$ as reference electrode, and a Pt counter electrode (See Supplemental Information for details).

Figure S1 shows the cyclic voltammograms from which we estimated the energy level of the highest occupied molecular orbital $\left(E_{\mathrm{HOMO}}\right)$, relative to vacuum, from the formal half-wave potential $E_{1 / 2}$, using eq. 5, where $e$ is the elementary charge $(\mathrm{eV})$, 
$E_{\text {abs,NHE }}$ is the absolute potential energy of the normal hydrogen electrode (NHE), or $4.5 \mathrm{eV}$, and $E_{1 / 2, \mathrm{NHE}}$ is the $E_{1 / 2}$ vs. NHE.

$$
E_{\text {Hомо }}=E_{\text {abs, NHE }}-e E_{1 / 2, \mathrm{NHE}}
$$

Table 2 shows the values of $E_{1 / 2, \mathrm{NHE}}$ and $E_{\mathrm{HOMO}, \mathrm{Fc}}$ for all SAMs.

The surface coverage $(I)$ was determined from the cyclic voltammograms (See Supplemental information for details) using eq. $6\left(Q_{\text {tot }}=\right.$ the total charge $(\mathrm{C}), n=$ is the number of electron per mole of reaction, $F=$ Faraday's constant $(96,485 \mathrm{C} / \mathrm{mol})$, and $A=$ the surface area of the electrode $\left.\left(\mathrm{cm}^{2}\right)\right){ }^{65}$

$$
\Gamma=Q_{\mathrm{tot}} / n F A
$$

Table 2 shows that the surface coverages of the $\mathrm{SAMs}$ of $\mathrm{SC}_{6} \mathrm{FcC}_{5} \mathrm{CH}_{3}$ and $\mathrm{SC}_{11} \mathrm{Fc}_{2}$ are significantly lower (about 20\%) than the surface coverages of the $\mathrm{SAMs}$ of $\mathrm{SC}_{9} \mathrm{Fc}$ and $\mathrm{SC}_{11} \mathrm{Fc}$. Our measured values of $\Gamma$ are close to those calculated assuming hexagonal packing of the $\mathrm{Fc}$ groups as spheres with a diameter of $6.6 \AA$ (the theoretical value of $\Gamma$ $\mathrm{SC} 11 \mathrm{Fc}$ is $\left.4.5 \times 10^{-10} \mathrm{~mol} / \mathrm{cm}^{2}\right)^{64}$, and similar to values reported in literature. ${ }^{63,66}$ Thus, the SAMs are densely packed, although SAMs of $\mathrm{SC}_{6} \mathrm{FcC}_{5} \mathrm{CH}_{3}$ and $\mathrm{SC}_{11} \mathrm{Fc}_{2}$ are less densely packed and probably have more defects than $\mathrm{SAMs}$ of $\mathrm{SC}_{9} \mathrm{Fc}$ and $\mathrm{SC}_{11} \mathrm{Fc}$.

Statistical Analysis of the Data Obtained with the Junctions. To discriminate artifact from real data, and to determine yields of working devices and the significance of the rectification ratio, we recorded and analyzed large numbers of data $(\mathrm{N}=300-1000)$ of each type of junction (Table 3). We did not select or exclude any data prior to our analysis; all plotting and fitting of histograms took into account every measured value of $J$ at a given voltage. We have reported the procedure for this statistical analysis before, ${ }^{23}$ but we give a brief description here. 
Table 2: Electrochemical Data Showing the $E_{1 / 2, \mathrm{NHE}}(\mathrm{V})$, Energy Level of the HOMO, and the Surface Coverage.

\begin{tabular}{llll}
\hline SAM & $\boldsymbol{E}_{\mathbf{1} / 2, \mathrm{NHE}}(\mathbf{V})$ & $\begin{array}{l}\text { HOMO } \\
(\mathbf{e V})\end{array}$ & $\begin{array}{l}\text { Surface } \\
\text { Coverage } \\
\left(\mathbf{m o l} / \mathbf{c m}^{2}\right)\end{array}$ \\
\hline $\mathrm{SC}_{11} \mathrm{Fc}$ & $0.545 \pm 0.007$ & $-5.0 \mathrm{eV}$ & $4.9 \pm 0.4 \times 10^{-10}$ \\
$\mathrm{SC}_{11} \mathrm{Fc}_{2}$ & $0.418 \pm 0.002$ & $-4.9 \mathrm{eV}$ & $4.0 \pm 0.2 \times 10^{-10}$ \\
$\mathrm{SC}_{9} \mathrm{Fc}$ & $0.526 \pm 0.004$ & $-5.0 \mathrm{eV}$ & $4.8 \pm 0.4 \times 10^{-10}$ \\
$\mathrm{SC}_{6} \mathrm{FcC}_{5} \mathrm{CH}_{3}$ & $0.521 \pm 0.007$ & $-5.0 \mathrm{eV}$ & $4.0 \pm 0.4 \times 10^{-10}$ \\
\hline
\end{tabular}


Figure 5A shows a histogram of all 997 values of $|J|$ collected at $V=-1.0 \mathrm{~V}$ on 53 $\mathrm{Ag}^{\mathrm{TS}}-\mathrm{SC}_{11} \mathrm{Fc} / / \mathrm{Ga}_{2} \mathrm{O}_{3} / \mathrm{EGaIn}$ junctions (we measured $21 J(\mathrm{~V})$ traces for each junction, one trace $=0 \mathrm{~V} \rightarrow+1 \mathrm{~V} \rightarrow-1 \mathrm{~V} \rightarrow 0 \mathrm{~V})$. The Gaussian fit to this histogram gives the log-mean and log-standard deviation for $|J(-1 \mathrm{~V})|$. Plotting and fitting the histogram of $|J|$ for each applied voltage yielded the corresponding log-means and log-standard deviations of $|J|$ (eq. 4). In the black "average trace" in figure 5B, these log-means determine the data points, while the log-standard deviations determine the error bars (white). The average trace is superimposed on all 997 traces (Fig. 5B, gray) recorded for the $\mathrm{Ag}^{\mathrm{TS}}$ $\mathrm{SC}_{11} \mathrm{Fc} / / \mathrm{Ga}_{2} \mathrm{O}_{3} / \mathrm{EGaIn}$ junctions.

We calculated 997 values of $R$ - one for each measured $J(\mathrm{~V})$ trace. We plotted all values of $R$ in histograms against which we fitted a Gaussian function to obtain the logmean and the log-standard deviation of $R$ for $\mathrm{Ag}^{\mathrm{TS}}-\mathrm{SC}_{11} \mathrm{Fc} / / \mathrm{Ga}_{2} \mathrm{O}_{3} / \mathrm{EGaIn}$ junctions. We repeated this procedure - for constructing the average trace and determining the value of $R$ - with each type of SAM measured. Figure 6 shows the average traces (the error bars indicate the log-standard deviation), and the histograms of the values of $R$ (with Gaussian fits to these histograms), for each junction.

All types of junctions i) are stable (hundreds of traces usually can be measured without short-circuits or large fluctuations; ${ }^{23}$ in fact, we usually completed the acquisition of the data, and stopped the experiment, well before the junctions failed), ii) have high yields in working devices (70-90\%), where a "working device" is defined as one that is stable over $>21$ cycles (the number of cycles measured in the present study) and does not short-circuit (Table 3), and iii) have reproducible rectification ratios (Fig. 6). 
Table 3: Statistics for the $\mathrm{Ag}^{\mathrm{TS}}-\mathrm{SR} / / \mathrm{Ga}_{2} \mathrm{O}_{3} / \mathrm{EGaIn}$ Junctions.

\begin{tabular}{|c|c|c|c|c|c|c|c|}
\hline $\begin{array}{l}\text { Type of } \\
\text { SAM (SR) }\end{array}$ & $\begin{array}{l}\text { Total } \\
\text { substrates }\end{array}$ & $\begin{array}{l}\text { Total } \\
\text { junctions }\end{array}$ & $\begin{array}{l}\text { Total traces } \\
\text { in } \\
\text { histogram }\end{array}$ & $\begin{array}{l}\text { Short- } \\
\text { circuits }\end{array}$ & $\begin{array}{l}\text { Unstable } \\
\text { junctions } \\
(\%)^{\mathrm{b}}\end{array}$ & $\begin{array}{l}\text { Yield } \\
(\%)^{c}\end{array}$ & $\begin{array}{l}\text { Rectification } \\
\text { ratio }(R)^{\mathrm{d}}\end{array}$ \\
\hline $\mathrm{SC}_{10} \mathrm{CH}_{3}$ & 4 & 23 & 415 & $4(17 \%)$ & $3(13)$ & 70 & $1.5(1.4)^{\mathrm{e}}$ \\
\hline $\mathrm{SC}_{14} \mathrm{CH}_{3}$ & 5 & 14 & 287 & $0(0 \%)$ & $3(21)$ & 79 & $2.1(2.5)^{\mathrm{e}}$ \\
\hline $\mathrm{SC}_{9} \mathrm{Fc}$ & 8 & 22 & 415 & $6(9 \%)$ & $3(23)$ & 68 & $10(6.8)$ \\
\hline $\mathrm{SC}_{11} \mathrm{Fc}$ & 10 & 53 & 997 & $3(5.6 \%)$ & $4(7.4)$ & 87 & $1.0 \times 10^{2}(3.0)^{\mathrm{e}}$ \\
\hline $\mathrm{SC}_{11} \mathrm{Fc}_{2}$ & 8 & 25 & 361 & $5(20 \%)$ & $3(12)$ & 68 & $5.0 \times 10^{2}(3.5)$ \\
\hline $\mathrm{SC}_{6} \mathrm{FcC}_{5} \mathrm{CH}_{3}$ & 3 & 33 & 538 & $0(0 \%)$ & $7(21)$ & 79 & $1.2(1.7)$ \\
\hline
\end{tabular}

${ }^{\mathrm{a}}$ number of template-stripped silver substrates at which we formed the SAMs

${ }^{\mathrm{b}}$ We define unstable junctions as those that gave $J(\mathrm{~V})$ curves that fluctuated; these junctions shorted

${ }^{\mathrm{c}}$ The yield is defined as working junctions that gave stable $J(\mathrm{~V})$ characteristics

${ }^{\mathrm{d}} \mathrm{We}$ define the rectification ratio for junctions with SAMs of n-alkanethiolates and $\mathrm{SC}_{6} \mathrm{FcC}_{5} \mathrm{CH}_{3}$ as $R=|J(\mathrm{~V})| /|J(-\mathrm{V})|$, and for junctions with $\mathrm{SAMs}$ of $\mathrm{SC}_{11} \mathrm{Fc}_{\text {or }} \mathrm{SC}_{11} \mathrm{Fc}_{2}$ as $R=|J(-\mathrm{V})| /|J(\mathrm{~V})|$. The number between parentheses is the log-standard deviation $\left(\sigma_{\log }\right)$.

${ }^{\mathrm{e}}$ Same data as reported in reference 23. 
Figure 5: A) The histogram of the values of $J$ measured at $V=-1.0 \mathrm{~V}$ obtained for $\mathrm{Ag}^{\mathrm{TS}}$ $\mathrm{SC}_{11} \mathrm{Fc} / / \mathrm{Ga}_{2} \mathrm{O}_{3} / \mathrm{EGaIn}$ junctions, with a Gaussian fit to this histogram giving the logmean value of $J\left(\mu_{\log }\right)$ and the log-standard deviation $\left(\sigma_{\log }\right)$. The values of $\mu_{\log }$ at each $V$ are plotted in the average trace (B, black squares), where the error bars (white) are located a factor of $\sigma_{\log }$ above and below the log-mean, respectively. B) The average trace of the $\mathrm{Ag}^{\mathrm{TS}}-\mathrm{SC}_{11} \mathrm{Fc} / / \mathrm{Ga}_{2} \mathrm{O}_{3} / \mathrm{EGaIn}$ junctions superimposed over all 997 traces (gray) collected on these junctions. The three traces from junctions that short-circuited lie outside the scale of the figure $\left(|J| \sim 10^{4}\right)$ and are not shown. 


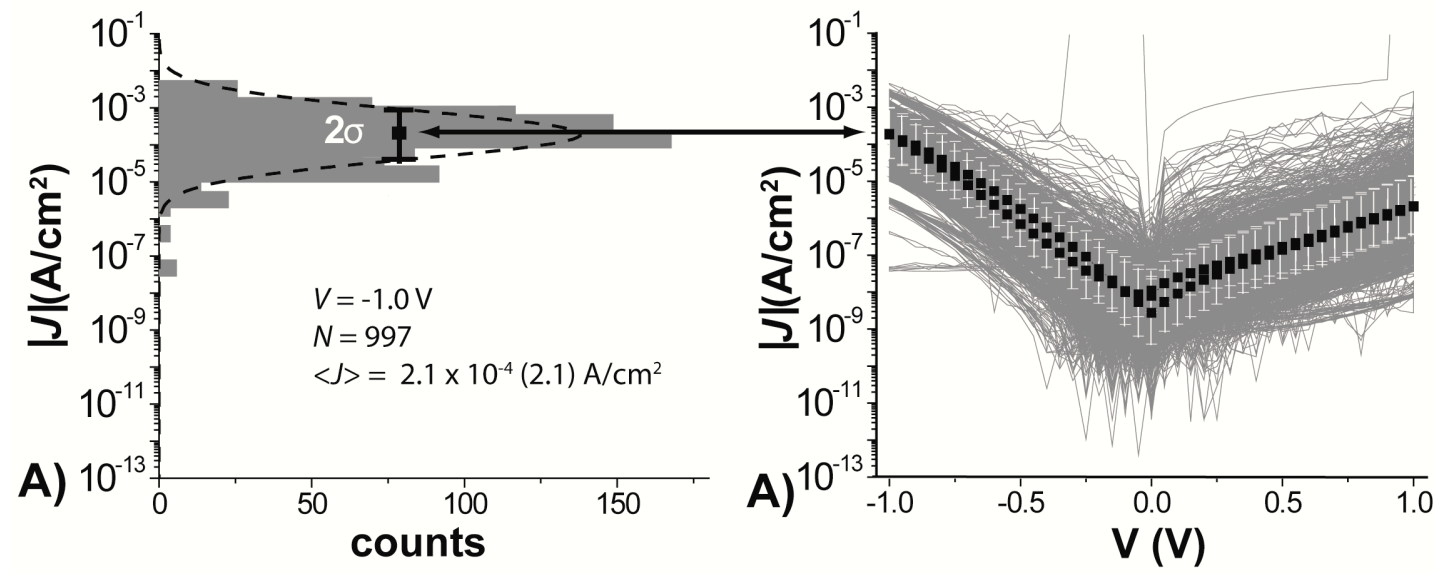


Figure 6: The average $|J|(\mathrm{V})$ curves of the $\mathrm{Ag}^{\mathrm{TS}}-\mathrm{SC}_{11} \mathrm{Fc}_{2} / / \mathrm{Ga}_{2} \mathrm{O}_{3} / \mathrm{EGaIn}(\mathrm{A})$, $\mathrm{Ag}^{\mathrm{TS}}-\mathrm{SC}_{11} \mathrm{Fc} / / \mathrm{Ga}_{2} \mathrm{O}_{3} / \mathrm{EGaIn}(\mathrm{B}), \mathrm{Ag}^{\mathrm{TS}}-\mathrm{SC}_{9} \mathrm{Fc} / / \mathrm{Ga}_{2} \mathrm{O}_{3} / \mathrm{EGaIn}(\mathrm{C})$, $\mathrm{Ag}^{\mathrm{TS}}-\mathrm{SC}_{6} \mathrm{FcC}_{5} \mathrm{CH}_{3} / / \mathrm{Ga}_{2} \mathrm{O}_{3} / \mathrm{EGaIn}(\mathrm{D}), \mathrm{Ag}^{\mathrm{TS}}-\mathrm{SC}_{10} \mathrm{CH}_{3} / / \mathrm{Ga}_{2} \mathrm{O}_{3} / \mathrm{EGaIn}(\mathrm{E})$, and $\mathrm{Ag}^{\mathrm{TS}}-\mathrm{SC}_{14} \mathrm{CH}_{3} / / \mathrm{Ga}_{2} \mathrm{O}_{3} / \mathrm{EGaIn}(\mathrm{F})$ junctions. The error bars are defined by the logstandard deviation, as in Figure 5 (see text). The dashed line is a guide for the eye placed at $J=10^{-5} \mathrm{~A} / \mathrm{cm}^{2}$. The histograms of the rectification ratios $R=|J(-\mathrm{V})| /|J(\mathrm{~V})|$ at $\pm 1 \mathrm{~V}$ with Gaussian fits to these histograms for the $\mathrm{Ag}^{\mathrm{TS}}-\mathrm{SC}_{11} \mathrm{Fc} / / \mathrm{Ga}_{2} \mathrm{O}_{3} / \mathrm{EGaIn}(\mathrm{G})$, $\mathrm{Ag}^{\mathrm{TS}}-\mathrm{SC}_{11} \mathrm{Fc}_{2} / / \mathrm{Ga}_{2} \mathrm{O}_{3} / \mathrm{EGaIn}(\mathrm{H})$, and $\mathrm{Ag}^{\mathrm{TS}}-\mathrm{SC}_{9} \mathrm{Fc} / / \mathrm{Ga}_{2} \mathrm{O}_{3} / \mathrm{EGaIn}$ (I) junctions. The histograms of the rectification ratios $R=|J(\mathrm{~V})| /|J(-\mathrm{V})|$ at $\pm 1 \mathrm{~V}$ with Gaussian fits to these histograms for the $\mathrm{Ag}^{\mathrm{TS}}-\mathrm{SC}_{6} \mathrm{FcC}_{5} \mathrm{CH}_{3} / / \mathrm{Ga}_{2} \mathrm{O}_{3} / \mathrm{EGaIn}(\mathrm{J}), \mathrm{Ag}^{\mathrm{TS}}-\mathrm{SC}_{10} \mathrm{CH}_{3} / / \mathrm{Ga}_{2} \mathrm{O}_{3} / \mathrm{EGaIn}$ $(\mathrm{K})$, and $\mathrm{Ag}^{\mathrm{TS}}-\mathrm{SC}_{14} \mathrm{CH}_{3} / / \mathrm{Ga}_{2} \mathrm{O}_{3} / \mathrm{EGaIn}(\mathrm{L})$ junctions. The dashed line is a guide for the eye placed at $R=1$. 

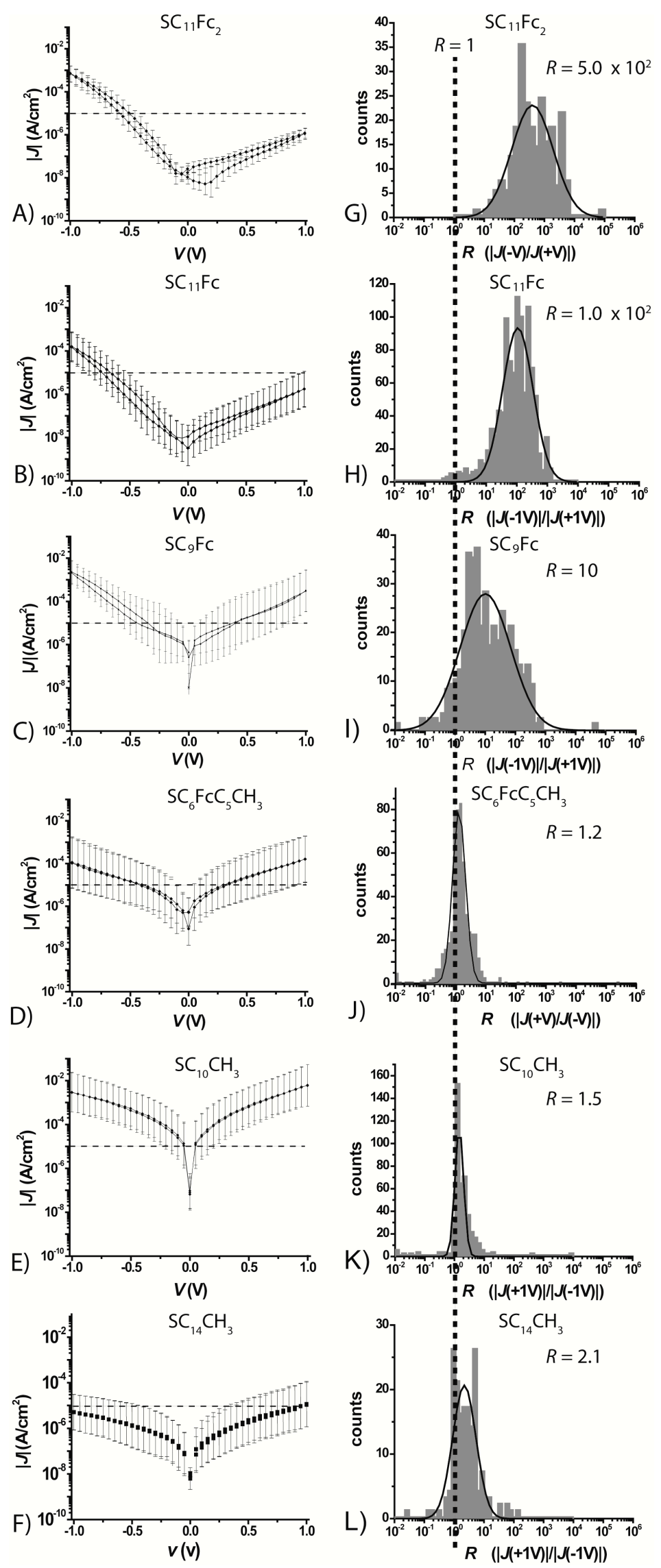
Rectification in Insulators: $\mathrm{Ag}^{\mathrm{TS}}-\mathrm{SC}_{\mathrm{n}-1} \mathrm{CH}_{3} / / \mathrm{Ga}_{2} \mathrm{O}_{3} / \mathbf{E G a I n}(\mathrm{n}=11$ or 15$)$. The $\mathrm{Ag}^{\mathrm{TS}}-\mathrm{SC}_{10} \mathrm{CH}_{3} / / \mathrm{Ga}_{2} \mathrm{O}_{3} / \mathrm{EGaIn}$ and $\mathrm{Ag}^{\mathrm{TS}}-\mathrm{SC}_{14} \mathrm{CH}_{3} / / \mathrm{Ga}_{2} \mathrm{O}_{3} / \mathrm{EGaIn}$ junctions rectify with values of $R$ close to unity (Table 3 ). ${ }^{23}$ Although the values of $R$ in these junctions are small $(R=1.5$ and 2.1$)$, a Student's t-test indicated that they differ significantly from unity, and a two-sample t-test indicated that they also differ from one another. ${ }^{23}$

Rectification in these junctions is unlikely to have a molecular origin, as there are a number of asymmetries in these junctions that have nothing to do with the structure of the molecules in the SAM: i) the electrodes have a small difference in work function $\left(\Phi_{\mathrm{Ag}} \approx\right.$ $4.7 \mathrm{eV}$ and $\Phi_{\mathrm{EGaIn}} \approx 4.3 \mathrm{eV}$ ), ii) the interfaces between the SAM and the two electrodes are entirely different (a covalent contact with Ag electrode and a van der Waals contact with the $\mathrm{Ga}_{2} \mathrm{O}_{3} / \mathrm{EGaIn}$ electrode), and iii) the $\mathrm{Ag}-\mathrm{SR}$ and the $\mathrm{Ga}_{2} \mathrm{O}_{3}$ interfacial layers are different. Given the small value of $R$ of the $\mathrm{Ag}^{\mathrm{TS}}-\mathrm{SC}_{\mathrm{n}-1} \mathrm{CH}_{3} / / \mathrm{Ga}_{2} \mathrm{O}_{3} / \mathrm{EGaIn}$ junctions, any of these asymmetries, or a combination thereof, may cause the small rectification. In any event, we believe these values of $R$ are too small to give meaningful information about the mechanism of rectification without extensive additional work.

\section{Rectification in $\mathbf{A g}^{\mathrm{TS}}{ }_{-} \mathbf{S C}_{\mathbf{1 1}} \mathbf{F c} / / \mathbf{G a}_{2} \mathbf{O}_{\mathbf{3}} / \mathbf{E G a I n}$. The $\mathrm{Ag}^{\mathrm{TS}}-\mathrm{SC}_{11} \mathrm{Fc} / / \mathrm{Ga}_{2} \mathrm{O}_{3} / \mathrm{EGaIn}$} junctions have values of $R$ of $1.0 \times 10^{2}$ (with a log-standard deviation of 3.3; Table 3) that are a factor of $\sim 10^{2}$ larger than that observed in junctions without the Fc moiety, i.e., $\mathrm{Ag}^{\mathrm{TS}}-\mathrm{SC}_{10} \mathrm{CH}_{3} / / \mathrm{Ga}_{2} \mathrm{O}_{3} / \mathrm{EGaIn}$ and $\mathrm{Ag}^{\mathrm{TS}}-\mathrm{SC}_{14} \mathrm{CH}_{3} / / \mathrm{Ga}_{2} \mathrm{O}_{3} / \mathrm{EGaIn}$ junctions. Therefore, the large rectification in junctions with the Fc moiety can only be caused by the asymmetry in the molecular structure of the $\mathrm{SC}_{11} \mathrm{Fc}$ molecules themselves, and by other asymmetries in the junctions, or to metal oxides. ${ }^{23}$ As mentioned above, junctions with $\mathrm{STM}^{49}$ and $\mathrm{Au}^{\mathrm{TS}}$ top-electrodes ${ }^{23}$ with $\mathrm{SAMs}$ of $\mathrm{SC}_{11} \mathrm{Fc}$ did also rectify currents. These studies 
concluded that the observed rectification was a molecular effect, and did not involve redox reactions between the redox-active $\mathrm{SC}_{11} \mathrm{Fc}$ and the $\mathrm{Ga}_{2} \mathrm{O}_{3} / E G a I n$ top-electrodes.

Potential Drops Inside the Junctions. Understanding the profile of the potential across these SAM-based tunneling junctions, at both forward and reverse bias, is important to understanding the mechanism of rectification. In this section we identify the components of the $\mathrm{Ag}^{\mathrm{TS}}-\mathrm{SAM} / / \mathrm{Ga}_{2} \mathrm{O}_{3} / \mathrm{EGaIn}$ junctions across which the applied potential may drop. The following sections describe a systematic study varying the potential drops across the SAM by varying the lengths of the "conductive" and "insulating" parts of the SAM. The resulting data enable the construction of a model for the mechanism of rectification.

Figure 7 shows energy level diagrams for the $\mathrm{Ag}^{\mathrm{TS}}-\mathrm{SAM} / / \mathrm{Ga}_{2} \mathrm{O}_{3} / \mathrm{EGaIn}$ junctions without any applied bias (i.e., an open circuit). Five parts of the junctions contribute to the profile of the potential in the junction. i) The Ag-S interface: the potential drop across the Ag-S contact is very small, and certainly much less than across the alkyl chain. ii) The alkyl chain: the potential drop across this insulating portion of the SAM is probably large due its large HOMO-LUMO gap and lack of conjugation. iii) The Fc or $F c_{2}$ moiety: the potential drop across this conductive part of the SAM depends on the applied bias (See Figure 8; the next section gives a detailed explanation). iv) The $\mathrm{SAM} / / \mathrm{Ga}_{2} \mathrm{O}_{3}$ interface: the potential drop across this (probably van der Waals) interface is significant but, we believe, less than across the alkyl chain. In the energy level diagram in Figure 8 we assumed a potential drop of $0.3 \mathrm{eV}$ across the $\mathrm{SAM} / / \mathrm{Ga}_{2} \mathrm{O}_{3}$ interface, which is probably an overestimation of the true value (see below) ${ }^{67} \mathrm{v}$ ) The layer of $G a_{2} \mathrm{O}_{3}$ : the potential drop across the $\mathrm{Ga}_{2} \mathrm{O}_{3}$ is not precisely known but is likely small, since the 
Figure 7: Energy level diagrams at open circuit for the $\mathrm{Ag}^{\mathrm{TS}}-\mathrm{SC}_{10} \mathrm{CH}_{3} / / \mathrm{Ga}_{2} \mathrm{O}_{3} / \mathrm{EGaIn}$ (A), $\mathrm{Ag}^{\mathrm{TS}}-\mathrm{SC}_{14} \mathrm{CH}_{3} / / \mathrm{Ga}_{2} \mathrm{O}_{3} / \mathrm{EGaIn}(\mathrm{B}), \mathrm{Ag}^{\mathrm{TS}}-\mathrm{SC}_{9} \mathrm{Fc} / / \mathrm{Ga}_{2} \mathrm{O}_{3} / \mathrm{EGaIn}(\mathrm{C})$, $\mathrm{Ag}^{\mathrm{TS}}-\mathrm{SC}_{6} \mathrm{FcC}_{5} \mathrm{CH}_{3} / / \mathrm{Ga}_{2} \mathrm{O}_{3} / \mathrm{EGaIn}(\mathrm{D}), \mathrm{Ag}^{\mathrm{TS}}-\mathrm{SC}_{11} \mathrm{Fc}_{2} / / \mathrm{Ga}_{2} \mathrm{O}_{3} / \mathrm{EGaIn}(\mathrm{E})$ and $\mathrm{Ag}^{\mathrm{TS}}-\mathrm{SC}_{11} \mathrm{Fc} / / \mathrm{Ga}_{2} \mathrm{O}_{3} / \mathrm{EGaIn}(\mathrm{F})$ junctions. Dashed lines indicate the width and height of the barriers. The barrier presented by the alkyl chain has a barrier height, defined by LUMO of the alkyl chain, of $-2.6 \mathrm{eV}$, and a barrier width, defined by the length of the alkyl chain, of $1.3 \mathrm{~nm}$. The HOMO levels of the $\mathrm{Fc}$ and $\mathrm{Fc}_{2}$ were estimated from the cyclic voltammograms (see text), and the LUMO level is approx. $-0.4 \mathrm{eV} .^{68,69}$ The width of the HOMO level of the $\mathrm{Fc}_{2}$ is approx. twice that of the HOMO level of the Fc. The barrier width and height of the van der Waals interface (vdW) are not known and are discussed in more detail in the text. Ag-S represents the silver-thiolate bond, $\mathrm{C}_{9}, \mathrm{C}_{11}, \mathrm{C}_{15}$, and $\mathrm{C}_{6}$ are alkyl chains, and $\mathrm{Fc}=$ ferrocene. 

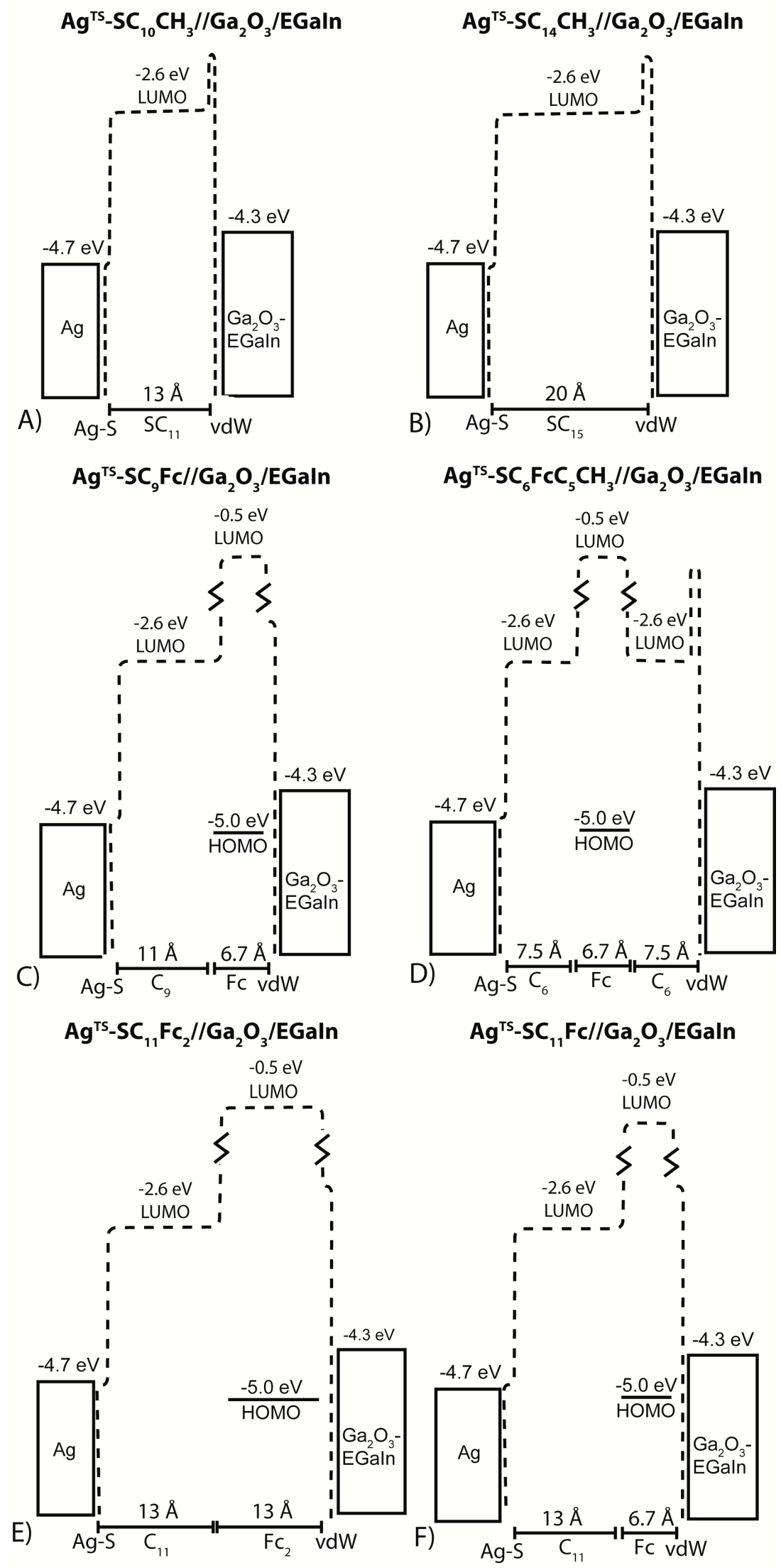
resistance of the layer of $\mathrm{Ga}_{2} \mathrm{O}_{3}$ is at least four orders of magnitude less than the resistance of a SAM of $\mathrm{SC}_{10} \mathrm{CH}_{3}$ (see Supplemental Information). ${ }^{23,32}$ Furthermore, the high dielectric constant of $\mathrm{Ga}_{2} \mathrm{O}_{3}(\sim 10)^{70}$ compared to that of SAMs of alkanethiols $(2.7)^{71}$ implies that the potential tends to drop along the SAM, rather than the $\mathrm{Ga}_{2} \mathrm{O}_{3}$.

We used the values for the Fermi levels of Ag and EGaIn reported in literature, and we estimated the value of the HOMO of the Fc by wet electrochemistry (Table 2). The HOMO $(-5.0 \mathrm{eV})$ level of the Fc group is slightly lower in energy than the work functions of the $\mathrm{Ag}(4.7 \mathrm{eV})^{72}$ and $\mathrm{Ga}_{2} \mathrm{O}_{3} / \mathrm{EGaIn}(4.3 \mathrm{eV})^{22}$ electrodes at open circuit (Fig. 7). These values, however, may deviate from the real values of energy levels in the junctions for three reasons. i) Immobilization of a SAM may increase or decrease the work function of the $\mathrm{Ag}^{\mathrm{TS}}$ by up to $1.0 \mathrm{eV}$ depending on the chemical structure of the SAM. ${ }^{73,74}$ In our junctions, however, this change is likely small, since Johansson et al. ${ }^{75}$ showed that the formation of SAMs of $\mathrm{SC}_{11} \mathrm{Fc}$ on $\mathrm{Au}$ increased the work function of $\mathrm{Au}$ by only $36 \mathrm{meV}$. ii) The HOMO level of the Fc was determined by wet electrochemical measurements of a SAM with the Fc units exposed to electrolyte solution. The Fc moieties inside the junctions experience an environment that is very different from an electrolyte solution. Since the HOMO level of the $\mathrm{Fc}$ is sensitive to this environment, the HOMO level in the junctions may differ from the value measured by wet electrochemistry by $0.1-0.5 \mathrm{eV} .^{44}$ iii) The Fermi level of the $\mathrm{Ga}_{2} \mathrm{O}_{3} / \mathrm{EGaIn}$ electrode in contact with the SAM might be different from that of bulk $\mathrm{Ga}_{2} \mathrm{O}_{3} / \mathrm{EGaIn}$. We do not know how the Femi level of the $\mathrm{Ga}_{2} \mathrm{O}_{3} / \mathrm{EGaIn}$ electrode changes once in contact with the SAM, but we assume that this change, as in the case of the bottom-electrode, is small. 
The Mechanism of Rectification. Figure 8 sketches the energy level diagrams of the $\mathrm{Ag}^{\mathrm{TS}}-\mathrm{SC}_{11} \mathrm{Fc} / / \mathrm{Ga}_{2} \mathrm{O}_{3} / \mathrm{EGaIn}, \mathrm{Ag}^{\mathrm{TS}}-\mathrm{SC}_{6} \mathrm{FcC}_{5} \mathrm{CH}_{3} / / \mathrm{Ga}_{2} \mathrm{O}_{3} / \mathrm{EGaIn}$ and $\mathrm{Ag}^{\mathrm{TS}}-\mathrm{SC}_{14} \mathrm{CH}_{3} / / \mathrm{Ga}_{2} \mathrm{O}_{3} / \mathrm{EGaIn}$ junctions under applied bias. In all of our experiments, we biased the $\mathrm{Ga}_{2} \mathrm{O}_{3} / \mathrm{EGaIn}$ top-electrode and grounded the $\mathrm{Ag}^{\mathrm{TS}}$ bottom-electrode.

The HOMO level couples more strongly to the $\mathrm{Ga}_{2} \mathrm{O}_{3} / \mathrm{EGaIn}$ top-electrode than to the $\mathrm{Ag}$ electrode since it is in close proximity to the former, and separated from the latter by the $\mathrm{SC}_{11}$ group. Under applied bias, the HOMO level follows the Fermi level of the $\mathrm{Ga}_{2} \mathrm{O}_{3} / \mathrm{EGaIn}$ electrode. At negative bias, the Fermi level of the $\mathrm{Ga}_{2} \mathrm{O}_{3} / \mathrm{EGaIn}$ electrode increases and, consequently, the HOMO level rises into the window between the Fermi levels of the two electrodes (Fig. 8A, right) and can participate in charge transport. In this case, the slowest (i.e., rate-limiting) step in charge-transport is tunneling through the $\mathrm{C}_{11}$ alkyl chain. At positive bias, the Fermi level of the $\mathrm{Ga}_{2} \mathrm{O}_{3} / \mathrm{EGaIn}$ electrode decreases and the HOMO level falls with it (Fig. 8A, left). Because the HOMO level remains below the Fermi levels of both electrodes, in the range of positive voltages applied, charges (holes or electrons) cannot classically flow through the HOMO. Instead, charges must tunnel through not only the $\mathrm{SC}_{11}$ group, but also the $\mathrm{Fc}$ moiety as well. At positive (reverse) bias, therefore, the width of the tunneling barrier increases by the length of the Fc moiety over the width of the tunneling barrier at negative (forward) bias.

The Potential Drop Across the van der Waal Interfaces. Some $(<5 \%)$ of the $\mathrm{Ag}^{\mathrm{TS}}-\mathrm{SC}_{11} \mathrm{Fc}_{2} / / \mathrm{Ga}_{2} \mathrm{O}_{3} /$ EGaIn junctions survived measurement up to $\pm 2.0 \mathrm{~V}$ without electrical failure (Fig. S4 shows nine $J(\mathrm{~V})$ curves for one junction out of five that were stable during measurement). These junctions had large values of $R \sim 1.0 \times 10^{3}-1.2 \times 10^{3}$ measured at $\pm 2.0 \mathrm{~V}$. At a bias of $+2.0 \mathrm{~V}$, the Fermi level of the top-electrode is $-6.5 \mathrm{eV}$, 
Figure 8: Proposed schematic representation of the energy level diagrams (with respect to vacuum) of the $\mathrm{Ag}^{\mathrm{TS}}-\mathrm{SC}_{11} \mathrm{Fc} / / \mathrm{Ga}_{2} \mathrm{O}_{3} / \mathrm{EGaIn}(\mathrm{A}), \mathrm{Ag}^{\mathrm{TS}}-\mathrm{SC}_{6} \mathrm{FcC}_{5} \mathrm{CH}_{3} / / \mathrm{Ga}_{2} \mathrm{O}_{3} / \mathrm{EGaIn}(\mathrm{B})$ and $\mathrm{Ag}^{\mathrm{TS}}-\mathrm{SC}_{10} \mathrm{CH}_{3} / / \mathrm{Ga}_{2} \mathrm{O}_{3} / \mathrm{EGaIn}(\mathrm{C})$ junctions at $1.0 \mathrm{~V}$ (left), $0 \mathrm{~V}$ (middle), and $-1.0 \mathrm{~V}$ (right) bias with $\mathrm{Ag}-\mathrm{S}=$ silver thiolate interface, $\mathrm{C}_{11}$ and $\mathrm{C}_{9}=$ alkyl chain, $\mathrm{Fc}=$ ferrocene, and $\mathrm{vdW}=$ the van der Waals contact of the SAM with the $\mathrm{Ga}_{2} \mathrm{O}_{3} / \mathrm{EGaIn}$. We biased $\mathrm{Ga}_{2} \mathrm{O}_{3} /$ EGaIn top-electrode and grounded the $\mathrm{Ag}^{\mathrm{TS}}$ bottom-electrode. We derived the value for the HOMO level at zero bias from wet electrochemistry (Table 2). The HOMO levels at negative and positive bias are qualitative estimates since we do not have quantitative data for the potential drops along the alkyl chain or across the van der Waals interface. The black dashed lines indicate the barrier widths and heights. The barrier height for the $\mathrm{C}_{11}$-alkyl chain is $-2.6 \mathrm{eV}$. The barrier height of the van der Waals contact is not known (and is discussed in more detail in the text), but is less than that of vacuum. The red dashed lines indicate the potential drops across the junctions when bias is applied. For the $\mathrm{Ag}^{\mathrm{TS}}-\mathrm{SC}_{6} \mathrm{FcC}_{5} \mathrm{CH}_{3} / / \mathrm{Ga}_{2} \mathrm{O}_{3} / \mathrm{EGaIn}$ junctions, the grey dashed lines indicate the potential drop for the case that the HOMO level of the Fc falls between the Fermi levels of the electrodes, and the red dashed line for the case it does not. 

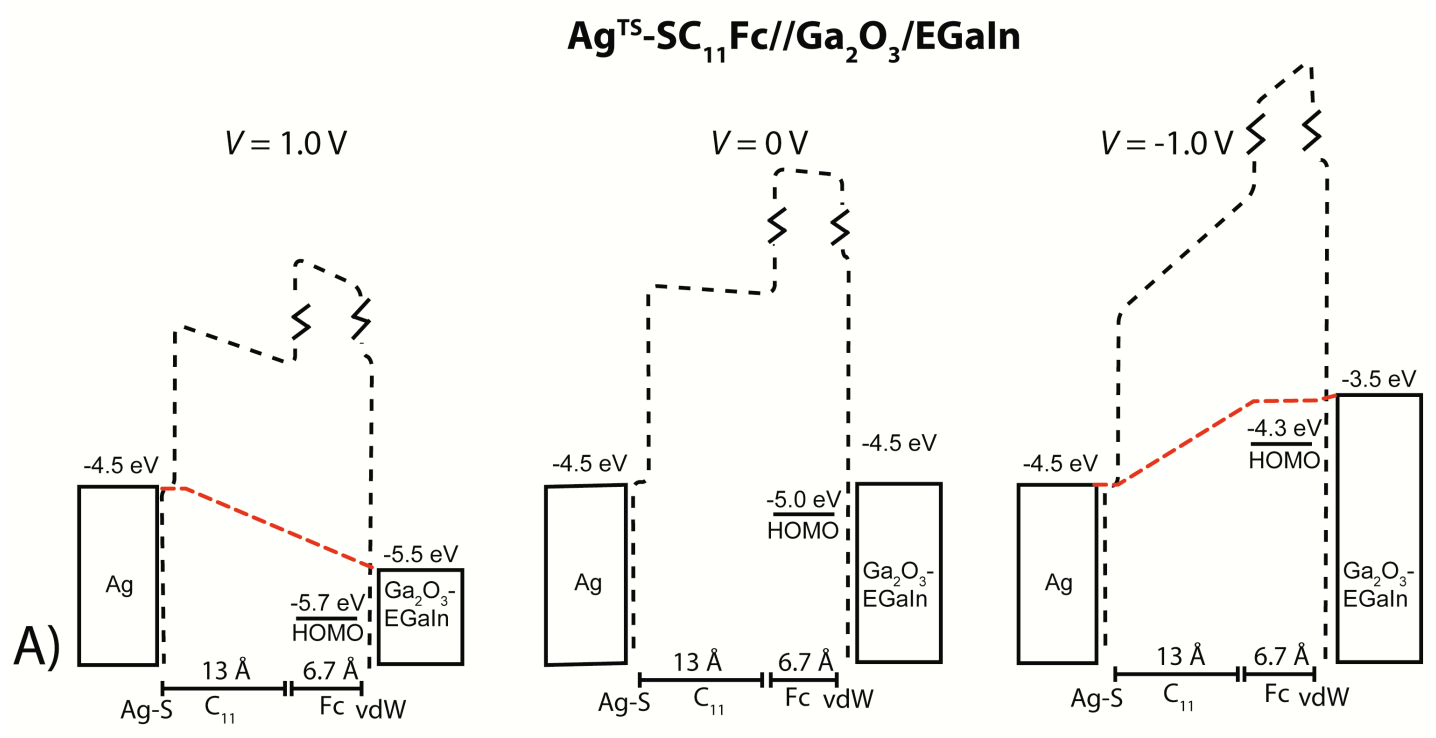

\section{$\mathrm{Ag}^{\mathrm{TS}}-\mathrm{SC}_{6} \mathrm{FcC}_{5} \mathrm{CH}_{3} / / \mathrm{Ga}_{2} \mathrm{O}_{3} / \mathrm{EGaln}$}
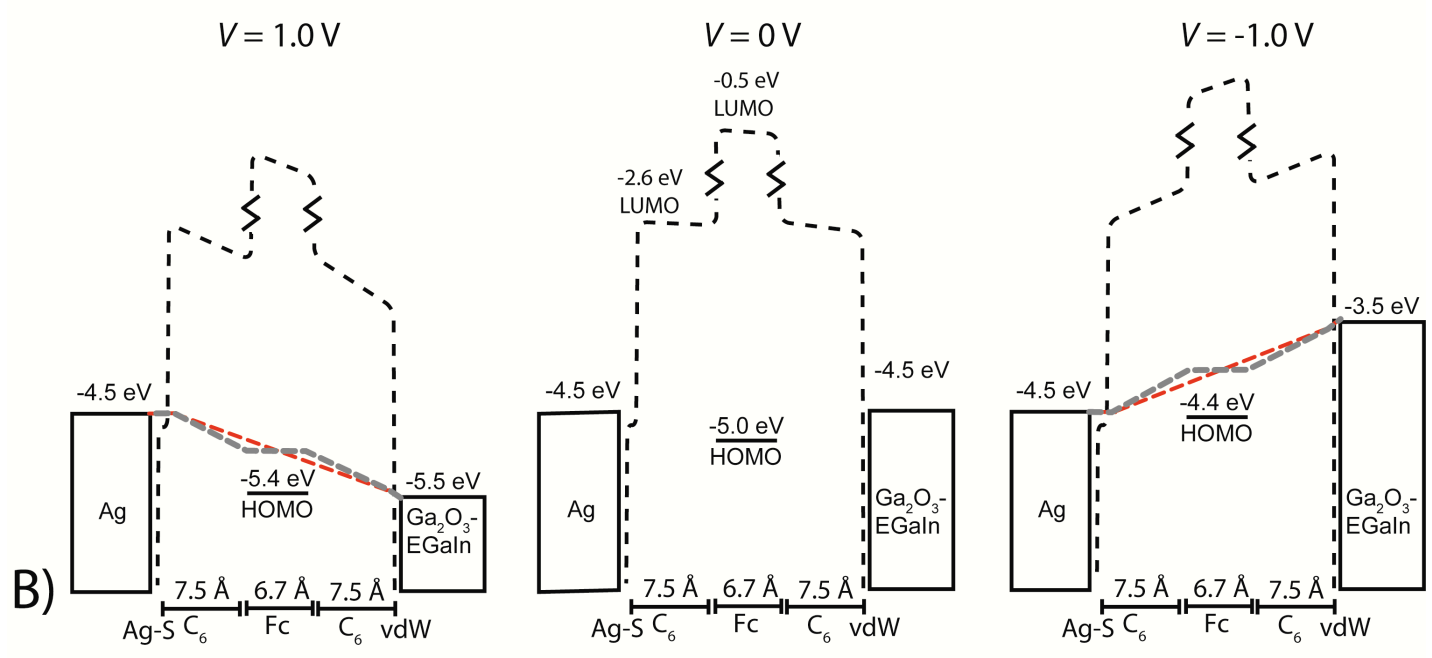

\section{$\mathrm{Ag}^{\mathrm{TS}}-\mathrm{SC}_{10} \mathrm{CH}_{3} / / \mathrm{Ga}_{2} \mathrm{O}_{3} / \mathrm{EGaln}$}
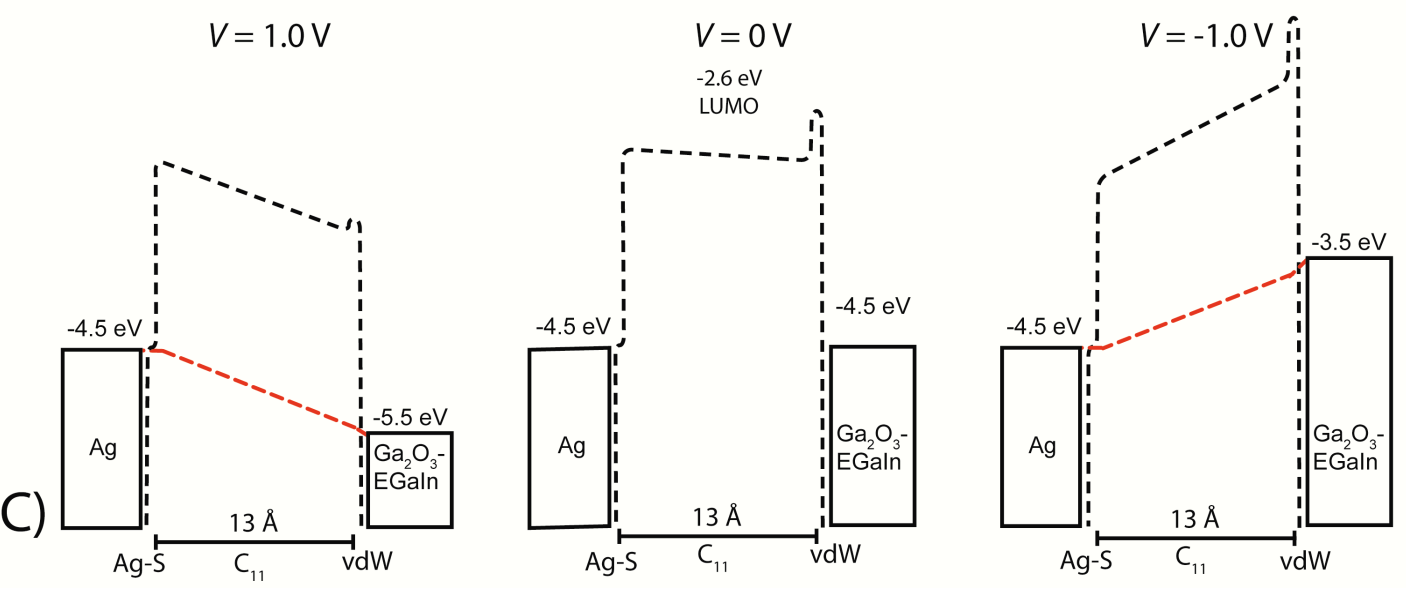
and the $\mathrm{HOMO}$ level would be $-6.4 \mathrm{eV}$ (if we assume a potential drop of $0.3 \mathrm{eV}$ per $1.0 \mathrm{~V}$ applied bias at the $\mathrm{SAM} / / \mathrm{Ga}_{2} \mathrm{O}_{3} / \mathrm{EGaIn}$ interface) and would theoretically participate in the charge transport, as it does at $-2.0 \mathrm{~V}$. We do not, however, observe a decrease in the rectification ratio measured at $\pm 2.0 \mathrm{~V}$, compared to that measured at $\pm 1.0 \mathrm{~V}$.

This observation suggests that the HOMO couples strongly to the $\mathrm{Ga}_{2} \mathrm{O}_{3} /$ EGaIn topelectrode, and that there is only a small potential drop across the SAM// $/ \mathrm{Ga}_{2} \mathrm{O}_{3} / \mathrm{EGaIn}$ interface. Thus, we do not believe that the HOMO falls between the Fermi levels of the electrodes (at least up to $+2.0 \mathrm{~V}$ ), and in the energy level diagram we probably overestimated the potential drop across the $\mathrm{SAM} / / \mathrm{Ga}_{2} \mathrm{O}_{3} / \mathrm{EGaIn}$ interface.

The Potential Drop Across the Conductive Part. To verify the proposed mechanism of rectification, we varied the potential drop across the conductive part of the SAM (the Fc group); we doubled the length of the conductive part by replacing the Fc with a $\mathrm{Fc}_{2}$ group.

The $J(\mathrm{~V})$ characteristics of junctions with $\mathrm{SAMs}$ of $\mathrm{SC}_{11} \mathrm{Fc}_{2}$ show two important characteristics (Fig. 6). i) The value of $R$ is five times larger for these junctions than for junctions with SAMs of $\mathrm{SC}_{11} \mathrm{Fc}$. ii) The value of $J$ at $+1.0 \mathrm{~V}$ is a factor of ten smaller for these junctions than for junctions with SAMs of $\mathrm{SC}_{14} \mathrm{CH}_{3}$.

The fact that the value of $R$ increases by a factor of five is in agreement with the model of Ford et al. ${ }^{35}$ Thus, varying the ratio of $d_{2} / d_{1}$ from 0.5 to 1.0 indeed does increase the rectification ratio (Table 1). The model proposed by Williams et al. ${ }^{1}$ ignores the potential drop across the HOMO - the Fc moiety - and does not predict a change of the value of $R$.

The fact that the value of $J(1 \mathrm{~V})$ through $\mathrm{Ag}^{\mathrm{TS}}-\mathrm{SC}_{11} \mathrm{Fc} / / \mathrm{Ga}_{2} \mathrm{O}_{3} / \mathrm{EGaIn}$ junctions is 
about an order of magnitude less than $J(1 \mathrm{~V})$ through similarly thick junctions of $\mathrm{Ag}^{\mathrm{TS}}-\mathrm{SC}_{14} \mathrm{CH}_{3} / / \mathrm{Ga}_{2} \mathrm{O}_{3} / \mathrm{EGaIn}\left(J \approx 10^{-6} \mathrm{~A} / \mathrm{cm}^{2}\right.$ and $10^{-5} \mathrm{~A} / \mathrm{cm}^{2}$, respectively) agrees with the model of Baranger and disagrees with the model of Williams. According to the model of Baranger, the potential drops nearly uniformly along the molecular rectifier when the HOMO does not overlap with the Fermi levels of the electrodes. In this regime, the Fc or $\mathrm{Fc}_{2}$ moiety acts as a tunneling barrier whose height is defined by the LUMO $(-0.5 \mathrm{eV})$ of the Fc moiety. The height of the barrier presented by the alkyl chain (we use a value for the LUMO of $-2.6 \mathrm{eV}^{76}$ ) is a subject of debate in the literature ${ }^{77}$ and may be less than that of the Fc moiety. In that case, the larger barrier height of the $\mathrm{Fc}$ moiety would (at least partially) explain the observation that the values of $J$ at positive bias are lower for the $\mathrm{Ag}^{\mathrm{TS}}-\mathrm{SC}_{11} \mathrm{Fc} / / \mathrm{Ga}_{2} \mathrm{O}_{3} / \mathrm{EGaIn}$ junctions than for $\mathrm{Ag}^{\mathrm{TS}}-\mathrm{SC}_{14} \mathrm{CH}_{3} / / \mathrm{Ga}_{2} \mathrm{O}_{3} / \mathrm{EGaIn}$ junctions, even though the two barriers have equal width. Thus, our results indicate that the potential drops significantly along the "conductive" part of the molecule, i.e., the Fc moiety, when the HOMO does not energetically overlap with the Fermi levels of the electrodes (Figure 8).

The thickness of the SAMs of $\mathrm{SC}_{11} \mathrm{Fc}_{2}$ is larger (by $0.6 \mathrm{~nm}$ ) than that of the $\mathrm{SC}_{11} \mathrm{Fc}$ SAMs, according to CPK models (Figure 7). Since, at positive bias the thickness of the SAM defines the width, $d$ (eq. 2), of the tunneling barrier, we expect the current density through the $\mathrm{SC}_{11} \mathrm{Fc}_{2} \mathrm{SAMs}$ at positive bias to be less, by at least a factor of 10 , than that of the $\mathrm{SC}_{11} \mathrm{Fc} \mathrm{SAM}$; we observed that the difference in current density was only a factor 2.5, but was still statistically significant according to a two-sample t-test (see Supplemental Information for details). To rationalize this discrepancy, we note that electrochemical data indicate a $\sim 20 \%$ lower coverage of the electrode by SAMs of 
$\mathrm{SC}_{11} \mathrm{Fc}_{2}$ than by SAMs of $\mathrm{SC}_{11} \mathrm{Fc}$. We infer that the $\mathrm{SAMs}$ of $\mathrm{SC}_{11} \mathrm{Fc}_{2}$ are less ordered than the $\mathrm{SAMs}$ of $\mathrm{SC}_{11} \mathrm{Fc}$ and are thus thinner than $\mathrm{CPK}$ models predict. Consequently, we underestimated the value of $J$ by failing to account for the lower than expected surface coverage of $\mathrm{SC}_{11} \mathrm{Fc}_{2}$.

The greater disorder, implied by electrochemical measurements, in $\mathrm{SAMs}$ of $\mathrm{SC}_{11} \mathrm{Fc}_{2}$ compared to $\mathrm{SAMs}$ of $\mathrm{SC}_{11} \mathrm{Fc}$ might also give rise to the broader distributions of $J$ and $R$ observed in the former than in the latter (Table 3 and Fig. 6).

Controlling the position of the Conductive Part inside the Junction. According to the theory of Williams et al. ${ }^{1}$ the rectification ratio should be 1 when the conductive part is positioned in the middle of the tunneling junction $\left(L_{1} / L_{2}=1\right.$, Table 1$)$; we positioned the $\mathrm{Fc}$ moiety in the middle of the junction by introducing $\mathrm{C}_{6}$ alkyl groups on either side.

Placement of the of the $\mathrm{Fc}$ moiety in the middle of the junctions by replacing the SAMs of $\mathrm{SC}_{11} \mathrm{Fc}$ with $\mathrm{SAMs}$ of $\mathrm{SC}_{6} \mathrm{FcC}_{5} \mathrm{CH}_{3}$ altered two characteristics in the $J(\mathrm{~V})$ curves. i) The rectification ratio decreased by two orders of magnitude to nearly unity. ii) The current density increased at $1.0 \mathrm{~V}$ by a factor of $\sim 100$, but remained nearly the same at $-1.0 \mathrm{~V}$.

These observations are in agreement with the models of Baranger and Williams (the model of Ford et al. makes no relevant prediction; this junction can be considered a tunneling junction that has three barriers determined by the one $\mathrm{Fc}$ and two $\mathrm{C}_{6}$ moieties a case which has not been treated by Ford et al. ${ }^{35}$ ). Thus, this experiment supports the above conclusion that asymmetric coupling of the HOMO level of the molecule with the $\mathrm{Ga}_{2} \mathrm{O}_{3} /$ EGaIn top-electrode is required for rectification.

Figure 8B shows how the mechanism of rectification we propose for the Fc- 
terminated SAMs also explains the experimental data for the $\mathrm{Ag}^{\mathrm{TS}}-\mathrm{SC}_{6} \mathrm{FcC}_{5} \mathrm{CH}_{3} / / \mathrm{Ga}_{2} \mathrm{O}_{3} / \mathrm{EGaIn}$ junctions. The HOMO level of the Fc moiety in the $\mathrm{Ag}^{\mathrm{TS}}-\mathrm{SC}_{6} \mathrm{FcC}_{5} \mathrm{CH}_{3} / / \mathrm{Ga}_{2} \mathrm{O}_{3} / \mathrm{EGaIn}$ junctions is separated from both electrodes by $\mathrm{C}_{6}$ alkyl moieties. Figure 8B shows that the HOMO of the Fc may participate in charge transport at $\mathrm{V}=1.0 \mathrm{~V}$, but is less likely to do so at $\mathrm{V}=-1.0 \mathrm{~V}$, and thus, rectification might occur with larger currents at positive bias than at negative bias. The difference, as depicted in Fig. $8 \mathrm{~B}$, between the HOMO level and the Fermi levels of the $\mathrm{Ag}$ and $\mathrm{Ga}_{2} \mathrm{O}_{3} / \mathrm{EGaIn}$ electrode at $\mathrm{V}= \pm 1.0 \mathrm{~V}$ is only $-0.1 \mathrm{eV}$. As mentioned earlier, the values of the Fermi levels and the HOMO levels are rough estimates. Given the uncertainties in estimating the values of the Fermi levels of the electrodes and the HOMO of the Fc inside the junctions, we can not determine whether the HOMO level of the Fc moiety in the $\mathrm{Ag}^{\mathrm{TS}}-\mathrm{SC}_{6} \mathrm{FcC}_{5} \mathrm{CH}_{3} / / \mathrm{Ga}_{2} \mathrm{O}_{3} / \mathrm{EGaIn}$ junctions participates in charge transport.

In any case, the observed value of $R$ is a factor of $10^{2}$ smaller for junctions of $\mathrm{Ag}^{\mathrm{TS}}-\mathrm{SC}_{6} \mathrm{FcC}_{5} \mathrm{CH}_{3} / / \mathrm{Ga}_{2} \mathrm{O}_{3} / \mathrm{EGaIn}$ than for junctions of $\mathrm{Ag}^{\mathrm{TS}}-\mathrm{SC}_{11} \mathrm{Fc} / / \mathrm{Ga}_{2} \mathrm{O}_{3} / \mathrm{EGaIn}$, but is similar to the value of $R$ measured for junctions of $\mathrm{Ag}^{\mathrm{TS}}-\mathrm{SC}_{\mathrm{n}-1} \mathrm{CH}_{3} / / \mathrm{Ga}_{2} \mathrm{O}_{3} / \mathrm{EGaIn}$ (with $\mathrm{n}=11$ or 15 ). This result suggests that it is unlikely that a change in the work functions of $\mathrm{Ag}^{\mathrm{TS}}$ with covalently attached SAMs of $\mathrm{SC}_{\mathrm{n}-1} \mathrm{CH}_{3}$ or $\mathrm{SC}_{11} \mathrm{Fc}$ cause the large rectification of currents in junctions of $\mathrm{Ag}^{\mathrm{TS}}-\mathrm{SC}_{11} \mathrm{Fc} / / \mathrm{Ga}_{2} \mathrm{O}_{3} / \mathrm{EGaIn}$.

The Potential Drop Across the Insulating Part. Figure 6C shows the average $J(\mathrm{~V})$ curve and the histogram of the rectification ratios for the $\mathrm{Ag}^{\mathrm{TS}}-\mathrm{SC}_{9} \mathrm{Fc} / / \mathrm{Ga}_{2} \mathrm{O}_{3} / \mathrm{EGaIn}$ junctions. Reducing the length of the alkyl chain by two carbon atoms, i.e., replacing the $\mathrm{SC}_{11}$ by a $\mathrm{SC}_{9}$ chain, altered three $J(\mathrm{~V})$ characteristics. i) The value of the rectification ration decreased by a factor of ten. ii) The current densities increased by a factor of ten at 
$-1.0 \mathrm{~V}$ and a factor of $10^{2}$ at $1.0 \mathrm{~V}$. iii) The widths of the distributions of both the current densities and the rectification ratios increased (Table 3).

Table 1 shows that the model of Williams predicts a decrease in the value of $R$ upon shortening the insulating part of the molecule, while the model proposed by Ford predicts an increase in the value of $R$. Both models predict an increase in the values of $J$ as the width of the tunneling barrier posed by the insulator decreases. Our data show greater agreement with the model proposed by Williams than with the model proposed by Ford. Other factors, however, may complicate this assessment.

In general, SAMs with short alkyl groups are more liquid in character than SAMs with long alkyl groups; our electrochemical data indicated that $\mathrm{SAMs}$ of $\mathrm{SC}_{9} \mathrm{Fc}$ are less ordered than $\mathrm{SAMs}$ of $\mathrm{SC}_{11} \mathrm{Fc}$ and $\mathrm{SC}_{11} \mathrm{Fc}_{2}$. The disordered $\mathrm{SAMs}$ of $\mathrm{SC}_{9} \mathrm{Fc}$ may (at least partially) explain the smaller value of $R$ and the larger log-standard deviation for junctions incorporating $\mathrm{SC}_{9} \mathrm{Fc}$ SAMs than for those incorporating $\mathrm{SC}_{11} \mathrm{Fc}$ and $\mathrm{SC}_{11} \mathrm{Fc}_{2}$ SAMs (Table 3).

\section{Conclusions}

An Accessible Molecular Orbital, Asymmetrically Positioned in the Junction and

\section{Electronically Coupled to One Electrode, Achieves Rectification through Non-}

Uniform Potential Drops. A molecule consisting of an electrically "conductive" ferrocene moiety, and an "insulating" alkyl moiety, rectifies electrical current when the conductive moiety is placed asymmetrically between electrodes of $\mathrm{Ag}$ and $\mathrm{Ga}_{2} \mathrm{O}_{3} / \mathrm{EGaIn}$. The Fc moiety is in van der Waals contact with the $\mathrm{Ga}_{2} \mathrm{O}_{3} / \mathrm{EGaIn}$ top-electrode and is separated from the $\mathrm{Ag}^{\mathrm{TS}}$ bottom-electrode by the $\mathrm{SC}_{11}$ chain. We assume that the largest 
potential drop occurs across the insulating alkyl chain, and only a small drop occurs at the van der Waals interface. The HOMO level of $\mathrm{Fc}$ is lower by $\sim 0.5 \mathrm{eV}$ than the Fermi level of the nearest electrode, the $\mathrm{Ga}_{2} \mathrm{O}_{3} / \mathrm{EGaIn}$. The $\mathrm{HOMO}$ can only participate in charge transfer when it lies between the Fermi levels of the two electrodes, a condition that is only possible at negative bias and not at positive bias (over the range of biases applied). Furthermore, the participation of the $\mathrm{Fc}$ moiety in charge transport leads to greater current density than direct tunneling through the entire SAM.

\section{The $\mathrm{Ag}^{\mathrm{TS}}$-SAM//Ga $\mathrm{O}_{3} / \mathrm{EGaIn}$ Junctions Are a Useful Test-Bed to Perform} Physical-Organic Studies, but This System Also Has Disadvantages. The molecular rectifier used in this study, i.e., $\mathrm{SC}_{11} \mathrm{Fc}$, has a relatively simple chemical structure, and the SAMs of $\mathrm{SC}_{11} \mathrm{Fc}$ are structurally and electrochemically well-defined. Importantly, the chemical composition of the SAMs can be easily modified. We formed the SAMs on ultra-flat silver surfaces to minimize defects in the junctions. Three features of the topelectrodes, comprising conically-shaped tips of $\mathrm{Ga}_{2} \mathrm{O}_{3} / \mathrm{EGaIn}$, contribute to their

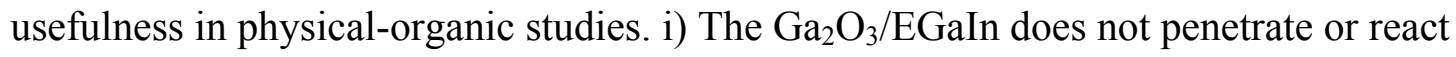
with the SAMs. ii) The $\mathrm{Ga}_{2} \mathrm{O}_{3} /$ EGaIn generates SAM-based tunneling junctions in high yields $(70-90 \%)$ and produces statistically large numbers of data. iii) $\mathrm{The} \mathrm{Ga}_{2} \mathrm{O}_{3} / \mathrm{EGaIn}$ generates junctions that are stable. Thus, this system makes it possible to study the mechanism of charge transport, and the mechanism of rectification, as a function of the chemical composition of the SAM.

This system has five disadvantages. i) We do not know the exact influence of the layer of $\mathrm{Ga}_{2} \mathrm{O}_{3}$ and the van der Waals interface on the $J(\mathrm{~V})$. We believe that the resistance of this layer is four orders of magnitude less than that of a SAM of 
$\mathrm{SC}_{10} \mathrm{CH}_{3}{ }^{23,32}$ ii) We do not know the roughness of the layer of $\mathrm{Ga}_{2} \mathrm{O}_{3}$. Preliminary results from scanning electron microscopy and optical microscopy (Supplemental Information) indicate that the surface is rough and that $\sim 25 \%$ of the $\mathrm{Ga}_{2} \mathrm{O}_{3}$ surface forms contacts with the SAMs. ${ }^{29}$ iii) We do not know the thickness of the layer of $\mathrm{Ga}_{2} \mathrm{O}_{3}$ inside the junctions, though we measured the thickness of the layer of $\mathrm{Ga}_{2} \mathrm{O}_{3}$ on cone-shaped tips of $\mathrm{Ga}_{2} \mathrm{O}_{3} /$ EGaIn to be $1.0-2.0 \mathrm{~nm}$ thick, ${ }^{57}$ and we have no reason to suspect that this value is different in the junctions. iv) We do not know all details of the layer $(\sim 1 \mathrm{~nm})$ of adsorbed organic material on the surface of the $\mathrm{Ga}_{2} \mathrm{O}_{3}$, nor its effects on charge transport. v) We do not know the nature of the interaction of the SAMs with the layer of $\mathrm{Ga}_{2} \mathrm{O}_{3}$, but assume that the both the $\mathrm{CH}_{3}$ - and Fc-termini form van der Waals contacts with the layer of $\mathrm{Ga}_{2} \mathrm{O}_{3}$.

\section{The Rectification in $\mathrm{Ag}^{\mathrm{TS}}-\mathrm{SC}_{11} \mathrm{Fc} / / \mathrm{Ga}_{2} \mathrm{O}_{3} / \mathbf{E G a I n}$ Junctions is Molecular in}

Origin. Junctions incorporating $\mathrm{Ag}$ and $\mathrm{Ga}_{2} \mathrm{O}_{3} / \mathrm{EGaIn}$ electrodes have five possible sources of asymmetry independent of the nature of the molecular component. i) The contact of the $\mathrm{Ga}_{2} \mathrm{O}_{3} / / \mathrm{EGaIn}$ top-electrode with the SAM is a van der Waals contact, while the contact with the Ag electrode and the SAM is covalent. ii) A thin layer of $\mathrm{Ga}_{2} \mathrm{O}_{3}$ is present at the top-electrode. iii) The difference in work function between EGaIn and $\mathrm{Ag}$ is $\sim 0.4 \mathrm{eV}$. iv) Layers of silver oxides or sulfides can form on the Ag electrodes. v) SAMs of $\mathrm{SC}_{\mathrm{n}-1} \mathrm{CH}_{3}$ on $\mathrm{Ag}^{\mathrm{TS}}$ may cause the substrate to have a different work function than SAMs of $\mathrm{SC}_{11} \mathrm{Fc}$ on $\mathrm{Ag}^{\mathrm{TS}}$; both cases may lead to a different work function than having no SAM at all.

We believe that the rectification in the $\mathrm{Ag}^{\mathrm{TS}}-\mathrm{SC}_{11} \mathrm{Fc} / / \mathrm{Ga}_{2} \mathrm{O}_{3} / \mathrm{EGaIn}$ junctions is a molecular effect for three reasons. i) Aged SAMs ( $>10 \mathrm{~h}$, ambient conditions) on Ag 
electrodes do not rectify currents. ${ }^{23}$ ii) Junctions of $\mathrm{Ag}^{\mathrm{TS}}-\mathrm{SC}_{\mathrm{n}-1} \mathrm{CH}_{3} / / \mathrm{Ga}_{2} \mathrm{O}_{3} / \mathrm{EGaIn}$ (with $\mathrm{n}$ $=11$ or 14) and $\mathrm{Ag}^{\mathrm{TS}}-\mathrm{SC}_{6} \mathrm{FcC}_{5} \mathrm{CH}_{3} / / \mathrm{Ga}_{2} \mathrm{O}_{3} / \mathrm{EGaIn}$, measured under the same conditions as the junctions of $\mathrm{Ag}^{\mathrm{TS}}-\mathrm{SC}_{11} \mathrm{Fc} / / \mathrm{Ga}_{2} \mathrm{O}_{3} / \mathrm{EGaIn}$, have rectification ratios close to unity. iii) SAMs of $\mathrm{SC}_{11} \mathrm{Fc}$ incorporated into junctions and measured with top-electrodes of $\mathrm{Au}^{23}$ and a tungsten STM tip ${ }^{49}$ also rectified currents (with $R=10-100$ ).

The Mechanism of Rectification is Entirely Dependent on Potential Drops. We determined the mechanism of charge transport by varying the potential drops within the junction; we varied the lengths of the conductive and insulating moieties, and placed the conducting moiety in the middle of the junction. These experiments indicate that a molecular rectifier can achieve large rectification ratios with a single molecular orbital that i) is located with spatial asymmetry in the junctions (so that it is strongly coupled to one electrode), and ii) is close (in energy) to the Fermi levels of the electrodes. We have demonstrated that achieving substantial rectification only requires a single conducting molecular orbital, and not separate donor and acceptor moieties.

Based on these observations, we propose a model for rectification in SAMs of $\mathrm{SC}_{11} \mathrm{Fc}$, in which a single molecular orbital (the HOMO, in this case) comes between the Fermi levels of the electrodes in only one direction of bias, and not in the other, because of asymmetric potential drops along the molecule. When the HOMO falls between the Fermi levels of the electrodes, the potential drops primarily along the $\mathrm{SC}_{11}$, when it does not lie between the Fermi levels of the electrodes, the potential drops more or less equally along both the $\mathrm{SC}_{11}$ and $\mathrm{Fc}$ moieties.

This Physical-Organic Study Is Useful for Evaluating Theoretical Models of

Rectification. Our proposed mechanism for rectification resembles the models of 
Baranger, ${ }^{2}$ Williams, ${ }^{1}$ and Ford et al. ${ }^{35}$ Williams and Baranger proposed molecular rectifiers that are similar in structure to ours, in that they have a HOMO or LUMO level asymmetrically coupled to the electrodes. The main difference between these two models is that Williams assumed that the potential drop along the conductive molecular orbital is not important, while Baranger calculated that it is important when the conducting molecular orbital does not overlap energetically with the Fermi levels of the electrodes. Ford et al.$^{35}$ calculated that double-barrier junctions can rectify currents with values of $R$ up to $\sim 22$. Our molecular rectifier can be treated as a double-barrier junction, but only when the HOMO is not accessible for charge transport (i.e., when it does not fall between the Fermi levels of the electrodes). In this model, the alkyl chain and the Fc moiety define the widths and heights of the barriers.

We changed the widths of the two barriers by changing the length of the alkyl moiety from $\mathrm{SC}_{11}$ to $\mathrm{SC}_{9}$, and the length of the $\mathrm{Fc}$ moiety from $\mathrm{Fc}_{\mathrm{c}}$ to $\mathrm{Fc}_{2}$. Replacing the $\mathrm{Fc}$ group with $\mathrm{Fc}_{2}$ increased the rectification ratio by a factor of five. This observation agrees with the models proposed by Ford ${ }^{35}$ and Baranger ${ }^{2}$, but disagrees with the model proposed by Williams. Reduction of the length of the alkyl chain from $\mathrm{C}_{11}$ to $\mathrm{C}_{9}$ decreased the rectification ratio by a factor of ten, which contradicts the model proposed by Ford et al. ${ }^{35}$, but agrees with the model proposed by Williams et al. ${ }^{1}$ Thus, our data supports the conclusion of Baranger, that the potential drop along the conductor is important. The potential drops along the Fc moiety when the HOMO is not energetically accessible for charge transport; the potential does not drop along the Fc moiety when the HOMO is accessible for charge transport. 


\section{The Rectification Ratios are a Factor 10 - 100 Larger than Predicted by Theory.}

Stadler et al. ${ }^{36}$ calculated that molecular rectifiers operating in the tunneling regime can not have values of $R$ exceeding $\sim 20$. Stadler et al. suggested that more complicated mechanisms of charge transport will be required for achieving molecular rectification with rectification ratio above $\sim 20$. We measured rectification ratios in $\mathrm{Ag}^{\mathrm{TS}}$ $\mathrm{SC}_{11} \mathrm{Fc}_{2} / / \mathrm{Ga}_{2} \mathrm{O}_{3} / \mathrm{EGaIn}$ junctions of 500 with a log-standard deviation of 3.5: that is, $68 \%$ of the data are in a range of $143-1750$. These large rectification ratios are not predicted by any of the theoretical models.

We performed measurements of $J(\mathrm{~V})$ as a function of temperature - measurements that are necessary to establish the mechanism of charge transport - and discussed these results in a separate paper. ${ }^{32}$ These measurements revealed that thermally activated charge transport is important in only one direction of bias, and not in the other. Our data, therefore, can only be partially explained by the models proposed of Baranger ${ }^{2}$, Williams ${ }^{1}$, and Ford et al. ${ }^{35}$ (or any combination thereof), because these models did not consider a bias-dependent change in the mechanisms of charge transport. In a separate paper we will discuss these temperature dependent data and elaborate further on the mechanism of charge transport in this type of molecular rectifier. ${ }^{78}$

\section{Acknowledgements}

The Netherlands Organization for Scientific Research (NWO) is kindly acknowledged for the Rubicon grant (C.A.N.) supporting this research. We acknowledge NSF (grant CHE05180055) for funding. 
Supplemental Information. The experimental procedures, details of the electrical properties of the layer of $\mathrm{Ga}_{2} \mathrm{O}_{3}$, wet electrochemistry, and data collection and statistical analysis. This material is available free of charge via the Internet at http://pubs.acs.org.

\section{References}

${ }^{1}$ Kornilovitch, P. E.; Bratkovsky, A. M.; Williams, R. S. Phys. Rev. B 2002, 66, 165436.

${ }^{2}$ Liu, R.; Ke, S-. H.; Yang, W.; Baranger, H. U. J. Chem. Phys. 2006, 124, 024718.

${ }^{3}$ Aviram, A.; Ratner, M. A. Chem. Phys. Lett. 1974, 29, 277.

${ }^{4}$ Metzger, R. M. Chem. Rev. 2003, 103, 3803.

${ }^{5}$ Endres, R. G.; Cox, D. L.; Singh, R. R. P. Rev. Mod. Phys. 2004, 76, 195.

${ }^{6}$ Grätzel, M. J Photochem. Photobiol. C Photochem Rev. 2003, 4, 145.

${ }^{7}$ McCreery, R. L. Chem. Mater. 2004, 16, 4477.

${ }^{8}$ Scott, J. C.; Bozano, L. D. Adv. Mater. 2007, 19, 1452

${ }^{9}$ Adams, D. M.; Brus, L.; Chidsey, C. E. D.; Creager, S.; Creutz, C.; Kagan, C. R.;

Kamat, P. V.; Lieberman, M.; Lindsay, S.; Marcus, R. A.; Metzger, R. M.; Michel-

Beyerle, M. E.; Miller, J. R.; Newton, M. D.; Rolison, D. R.; Sankey, O.; Schanze, K. S.;

Yardley, J.; Zhu, X. J. Phys. Chem. B 2003, 107, 6668.

${ }^{10}$ Collier, C. P.; Mattersteig, G.; Wong, E. W.; Luo, Y.; Beverly, K.; Sampaio, J.;

Raymo, F. M.; Stoddart, J. F.; Heath, J. R. Science 2000, 289, 1172.

${ }^{11}$ Collier, C. P.; Wong, E. W.; Belohradsky, M.; Raymo, F. M.; Stoddart, J. F.; Kuekes, P. J.; Williams, R. S.; Heath, J. R. Science 1999, 285, 391.

${ }^{12}$ Chen, J.; Reed, M. A.; Rawlett, A. M.; Tour, J. M. Science 1999, 286, 1550.

${ }^{13}$ Ashwell, G. J.; Ewinton, J.; Robinson, B. J. Chem. Comm. 2006, 618. 
${ }^{14}$ Kim, T. -W.; Wang, G.; Lee, H.; Lee, T. Nanotechnology 2007, 18, 315204.

${ }^{15}$ Bang, G. S.; Chang, H.; Koo, J. -R.; Lee, T.; Advincula, R. C.; Lee, H. Small 2008, 4,1399 .

${ }^{16}$ Fisher, G. L.; Walker, A. V.; Hooper, A. E.; Tighe,T. B.; Bahnck, K. B.; Skriba, H. T.;

Reinard, M. D.; Haynie, B. C.; Opila, R. L.; Winograd,N.; Allara, D. L. J. Am. Chem. Soc. 2002, 124, 5528.

${ }^{17}$ Walker, A. V.; Tighe, T. B.; Cabarcos, O. M.; Reinard, M. D.; Haynie, B. C.; Uppili, S.; Winograd, N.; Allara, D. L. J. Am. Chem. Soc. 2004, 126, 3954.

${ }^{18}$ Bebee, J. M.; Kushmerick, J. G. Appl. Phys. Lett. 2007, 90, 083117.

${ }^{19}$ Lau, C. N.; Stewart, D. R; Williams, R. S.; Bockrath, M. Nano Lett., 2004, 4, 569.

${ }^{20}$ Chabinyc, M. L.; Chen, X.; Holmlin, R. E.; Jacobs, H.; Skulason, H.; Frisbie, C. D.; Mujica, V.; Ratner, M. A.; Rampi, M. A.; Whitesides, G. M. J. Am. Chem. Soc. 2002, $124,11730$.

${ }^{21}$ Venkataraman, L.; Klare, J. E.; Nuckolls, C.; Hybertsen, M. S.; Steigerwald, M. L. Nature 2006, 442, 7105.

${ }^{22}$ Chiechi, R. C.; Weiss, E. A.; Dickey, M. D.; Whitesides, G. M. Angew. Chem., Int. Ed. 2008, 47,142

${ }^{23}$ Nijhuis, C. A.; Reus, W. F.; Whitesides, G. M. J. Am. Chem. Soc. 2009, 131, 17814.

${ }^{24}$ Joachim, C.; Ratner, M. A. Proc. Natl. Acad, Sci. USA 2005, 102, 8801.

${ }^{25}$ Weiss, E. A.; Chiechi, R. C.; Kaufman, G. K.; Kriebel, J. K.; Li, Z.; Duati, M.; Rampi, M. A.; Whitesides G. M. J. Am. Chem. Soc. 2007, 129, 4336.

${ }^{26}$ Love, J. C.; Estroff, L. A.; Kriebel, J. K.; Nuzzo, R. G.; Whitesides, G. M. Chem. Rev. 2005, 105, 1103. 
${ }^{27}$ Poirier, G. E. Chem. Rev. 1997, 97, 1117.

${ }^{28}$ Laibinis, P. E.; Whitesides, G. M.; Allara, D. L.; Tao, Y.-T; Parikh, A. N.; Nuzzo, R. G. J. Am. Chem. Soc. 1991, 113, 7152.

${ }^{29}$ Preliminary characterization of the tips of $\mathrm{Ga}_{2} \mathrm{O}_{3} / \mathrm{EGaIn}$ by scanning electron microscopy (SEM) indicates that the tips have a large surface roughness. Preliminary optical micrographs of cone-shaped tips of $\mathrm{Ga}_{2} \mathrm{O}_{3} / \mathrm{EGaIn}$ in contact with a glass substrate indicate that only $\sim 25 \%$ of the measured junctions size is in contact with the SAM.

${ }^{30}$ McCreery, R.; Dieringer, J.; Solak, A.. O.; Snyder, B.; Nowak, A. M.; McGovern, W. R.; DuVall S. J. Am. Chem. Soc. 2003, 125, 10748.

${ }^{31}$ Metzger, R. M. Acc. Chem. Res. 1999, 32, 950.

${ }^{32}$ Nijhuis, C. A.; Reus, W. F.; Barber, J. R.; Dickey, M. D. Whiteseides, G. M. Nano Lett. 2010, 10, 3611.

${ }^{33}$ The model does not account for a change in the mechanism of charge transport. Molecular orbitals that are energetically accessible may enable hopping.

${ }^{34}$ Larade, B.; Bratkovsky, M. A. Phys. Rev. B. 2003, 235305.

${ }^{35}$ Armstrong, N.; Hoft, R. C.; McDonagh, A.; Cortie, M. B.; Ford, M. J. Nano Lett. 2007, 7,3018

${ }^{36}$ Stadler, R.; Geskin, V.; Cornil, J. J. Phys.: Condens. Matter. 2008, 20, 374105.

${ }^{37}$ Lenfant, S.; Krzeminski, C.; Delerue, C.; Allan, G.; Vuillaume, D. Nano Lett. 2003, 3, 741.

${ }^{38}$ Metzger, R. M.; Chen, B.; Höpfner, U.; Lakshmikantham, M. V.; Vuillaume, D.;

Kawai, T.; Wu, X.; Tachibana, H.; Hughes, T. V.; Sakurai, H.; Baldwin, J. W.; Hosch, C.

Cava, M. P.; Brehmer, L.; Ashwell, G. J. J. Am. Chem. Soc. 1997, 119, 10455. 
${ }^{39}$ Metzger, R. M.; Xu, T.; Peterson, I. R. J. Phys. Chem. B 2001, 105, 7280.

${ }^{40}$ Metzger, R. M.; Tao, Xu.; Peterson, I. R. J. Phys. Chem. B 2001, 105, 7280

${ }^{41}$ Galperin, M.; Nitzan. A.; Sek S.; Majda, M. J. Electroanal. Chem. 2003, 550, 337.

${ }^{42}$ Lenfant, S.; Krzeminski, C.; Delerue, C.; Allan, G.; Vuillaume, D. Nano Lett. 2003, 3, 741.

${ }^{43}$ Peterson, I. R.; Vuillaume, D.; Metzger, R. M. J. Phys. Chem. A 2001, 105, 4702.

${ }^{44}$ Shumate, W. J.; Mattern, D. L.; Jaiswal, A.; Dixon, D. A.; White, T. R.; Burgess, J.;

Honciuc, A.; Metzger, R. M. J. Phys. Chem. B 2006, 110, 11146.

${ }^{45}$ Metzger, R. M. J. Mater. Chem. 1999, 9, 2027.

${ }^{46}$ Stokbro, K,; Taylor, J; Brandbyge, M. J. Am. Chem. Soc. 2003, 125, 3674

${ }^{47}$ Ng, M. -K.; Lee, D. -C.; Yu, L. J. Am. Chem. Soc. 2002, 124, 11862.

${ }^{48}$ Ashwell, G. J.; Urasinska, B.; Tyrrell, W. D. Phys. Chem. Chem. Phys. 2006, 8, 3314.

${ }^{49}$ Müller-Meskamp, L.; Karthäuser, S.; Zandvliet, H. J. W.; Homberger, M.; Simon, U.;

Waser, R. Small 2009, 5, 496.

${ }^{50}$ McCreery, R. L.; Kalakodimi, R. P. Phys. Chem. Chem. Phys. 2006, 8, 2572.

${ }^{51}$ Regan, M. J.; Tostmann, H.; Pershan, P. S.; Magnussen, O. M.; DiMasi, E.; Ocko, B.

M.; Deutsch, M. Phys. Rev. B: Condens. Matter 1997, 55, 10786.

${ }^{52}$ Dickey, M. D.; Chiechi, R. C.; Larson, R. J.; Weiss, E. A.; Weitz, D. A.; Whitesides, G. M. Adv. Funct. Mater. 2008, 18, 1097.

${ }^{53}$ York, R. L.; Nguyen, P. T.; Slowinski, K. J. Am. Chem. Soc. 2003, 125, 5948.

${ }^{54}$ Rampi, M. A.; Whitesides, G. M. Chem. Phys. 2002, 281, 373.

${ }^{55}$ Reus, W. F.; Nijhuis, C. A.; Barber, J.; Mwangi, M.; Cademartiri, L.; Kim, C.; York, R. L.; Liu, X.; Whitesides, G. M. unpublished results. 
${ }^{56}$ Lorenz, M. R.; Woods, J. F.; Gambino, R. J. J. Phys. Chem. Solids 1967, 28, 403.

${ }^{57}$ Cademartiri, L.; Mwangi, M. T.; Nijhuis, C. A.; Barber, J.; Sodhi, R. N. S.; Brodersen, P.; Kim, C.; Reus, W. F.; Whitesides, G. M. unpublished results.

${ }^{58}$ Chidsey, C. E. D. Science 1991, 251, 919.

${ }^{59}$ Yamada, M.; Nishihara, H. Langmuir, 2003, 19, 8050.

${ }^{60}$ Nishihara, H.; Bull. Chem. Soc. Jpn. 2001, 74, 19.

${ }^{61}$ Rowe, G. K.; Creager, S. E. Langmuir 1994, 10, 1186.

${ }^{62}$ Dong,T. -Y.; Chang, L. -S.; Tseng, I. -M.; Huang, S. -J. Langmuir 2004, 20, 4471.

${ }^{63}$ Creager, S. E.; Rowe, G. K. J. Electroanal. Chem. 1994, 370, 203.

${ }^{64}$ Rowe, G. K.; Creager, S. E. Langmuir 1991, 7, 2307.

${ }^{65}$ Bard, A. J.; Faulkner, L.R. Electrochemical Methods: Fundamentals and Applications John Wiley \& Sons: New York, 2001.

${ }^{66}$ Collard, D. M.; Fox, M. A. Langmuir 1991, 7, 1192.

${ }^{67}$ We assume that the $\mathrm{Ga}_{2} \mathrm{O}_{3}$ form a van der Waals contact with SAMs of alkanethiolates. For SAMs of alkanethiolates terminated with Fc groups, this contact might be more complex and involve other types of interactions, e.g., interactions of the aromatic rings of the $\mathrm{Fc}$ with ions in the $\mathrm{Ga}_{2} \mathrm{O}_{3}$ layer, or dipole-dipole interactions.

${ }^{68}$ Kitagawa, K.; Morita, T.; Kimura, S. J Phys. Chem. B 2005, 109, 13906.

${ }^{69}$ Tivanski, A. V.; Walker, G. C. J. Am. Chem. Soc. 2005, 127, 7647

${ }^{70}$ Passlack, M.; Hunt, N. E. J.; Schubert, E. F.; Zydzik, G. J.; Hong, M.; Mannaerts, J. P.; Opila, R. L.; Fischer, R. J. Appl. Phys. Lett. 1994, 64, 2715.

${ }^{71}$ Rampi, M. A.; Schueller, O. J. A.; Whitesides, G. M. Appl. Phys. Lett. 1998, 72, 1781.

${ }^{72}$ Lide, D. R. Handbook of Chemistry and Physics CRC Press, Inc.: Boca Raton, 1996. 
${ }^{73}$ de Boer, B.: Hadipour, A.; Mandoc, M. M.; van Woudenbergh, T.; Blom, P. W. M.

Adv. Mater. 2005, 17, 621,

${ }^{74}$ Rangger, G. M.; Romaner, L.; Heimel. G.; Zojer, E. Surf. Interface Anal. 2008, 40, 371

${ }^{75}$ Watcharinyanon, S.; Moons, E.; Johansson, L. S. O. J. Phys. Chem. C 2009, 113, 1972.

${ }^{76}$ Li, C. -P.; Wei, K. -H.; Huang, J. Y. Angew. Chem. Int. Ed. 2006, 45, 1449.

${ }^{77}$ Salomon, A.; Cahen, D.; Lindsay, S.; Tomfohr, J.; Engelkes, V. B.; Frisbie, C. D. $A d v$.

Mater. 2003, 15, 1881.

${ }^{78}$ Nijhuis, C. A.; Reus, W. F.; Whitesides, G. M. unpublished results. 



\section{TOC Graphic:}

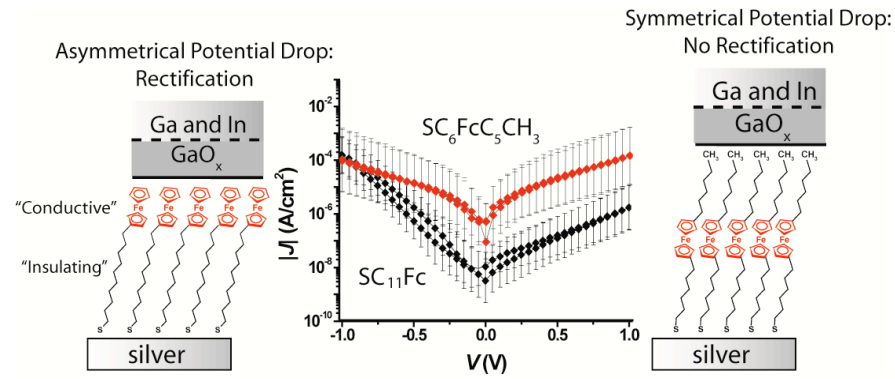

